\title{
El diseño de las instituciones en el Estado Sandinista (1979-1982): la revolución como fuente de derecho
}

\author{
por \\ María Dolores Ferrero Blanco \\ Universidad de Huelva
}

A medida que se iban perfilando en Nicaragua las instituciones del nuevo Estado revolucionario, se fue consolidando una constante que permanecería toda la década de 1980: la preeminencia del poder ejecutivo sobre los demás y la pérdida de los grandes apoyos iniciales del Frente Sandinista de Liberación Nacional (FSLN). Asimismo, el entendimiento entre Nicaragua y EE.UU., ya difícil en el contexto de la Guerra Fría, empeoró durante este período. El presente trabajo pretende dilucidar los diversos factores que generaron el desequilibrio de poderes del diseño institucional sandinista.

Palabras Clave: Frente Sandinista de Liberación Nacional (FSLN); Junta de Gobierno de Reconstrucción Nacional; Ronald Reagan; Dirección Nacional; Guerra de la Contra.

\section{INTRODUCCIÓN}

El Frente Sandinista de Liberación Nacional (FSLN) había nacido en Nicaragua durante la década de 1960 como un movimiento político-militar, vertical y clandestino e inspirado en la filosofía marxista, única fórmula con la que le fue posible sobrevivir en el seno de la dictadura de los Somoza. El movimiento fue creciendo y evolucionando en medio de un entorno hostil, plagado de injusticias, represión, enormes desequilibrios sociales e ineficacia absoluta de la oposición política legal. Su esfuerzo y lucha fueron cada vez más reconocidos por amplios sectores de la sociedad hasta el punto de encabezar una insurrección interclasista de toda la población. Sin embargo, derrotada la dictadura el 19 de julio de 1979, pronto hubo sectores descontentos del 
interior del país, que unidos a los residuos del régimen anterior y fuertemente sostenidos por EE.UU., terminarían por desencadenar la denominada «Guerra de la Contra». La hermosa revolución sandinista, que había concitado las simpatías y solidaridades del mundo entero, había sido tempranamente interferida por la contrarrevolución y, de ello como de cualquier otro error o carencia, se ha responsabilizado generalmente a la «agresión norteamericana»: a la guerra que ahondó la crisis económica, que interrumpió o imposibilitó el proyecto sandinista y que marcaría toda la década de su gobierno, de 1979 a 1990.

Es incuestionable que la Administración Reagan apostó decididamente en contra de la revolución nicaragüense, pero también las decisiones y actitudes sandinistas tuvieron su cuota de responsabilidad en las dificultades del gobierno, lo que obliga a plantearse ciertas preguntas: ¿qué objetivos persiguieron los sandinistas al diseñar el andamiaje institucional del Estado Revolucionario? ¿por qué los fueron abandonando sus antiguos colaboradores? ¿hubo comportamientos que explicaron la oposición frontal de EE.UU. o solo fue motivada por sus prejuicios previos?

Este trabajo pretende responder a algunas de estas cuestiones analizando el diseño de las instituciones - la composición y evolución de la Junta de Gobierno de Reconstrucción Nacional (JGRN), del Consejo de Estado y del Poder Judicial- y la clase de equilibrio que se estableció entre los tres poderes. Algo imprescindible para comprender el modelo que perseguía implantar el FSLN, siempre a través de su Dirección Nacional.

En el contexto de la Guerra Fría, se tomaron decisiones tanto por parte de EE.UU. como de Nicaragua que tensaron al máximo las relaciones. De un lado, Ronald Reagan se mostró contundente e inflexible en el propósito de frenar un gobierno que consideraba pro-soviético y que estaba sustituyendo al de los Somoza, que había sido durante más de cuarenta años el «gendarme anticomunista del Caribe». Para ello se sustentaba en la doctrina de la Seguridad Nacional y en acusar al sandinismo de comunista y de haber dado ya muestras de querer exportar la guerrilla, como había hecho antes Cuba. Por su parte, el FSLN, tras la experiencia durísima de la dictadura y la certeza de que la administración norteamericana no permitiría gobernar a quienes habían llegado al poder mediante una revolución, se aproximó a la URSS para contrarrestar la presión y ausencia de apoyo del rival. El desprestigio de los procesos electorales somocistas tampoco ayudó a la valoración de la democracia formal y, por el contrario, animó a admirar la alternativa sociopolítica que representaba el Bloque del Este.

Las primeras medidas tomadas por ambos gobiernos solo empeoraron la situación: la autodefinición marxista del FSLN ya en septiembre de 1979, la ayuda prestada a la guerrilla salvadoreña del Frente Farabundo Martí para la 
Liberación Nacional (FMLN) al poco tiempo del triunfo revolucionario, el anuncio de no convocar elecciones, las primeras leyes sobre confiscaciones y los primeros acuerdos entre Nicaragua y la URSS, irritarían sobremanera a EE.UU., aún meses antes de que Ronald Reagan tomara posesión, en enero de $1981^{1}$.

Del lado contrario, la suspensión de la ayuda prometida por J. Carter, el documento de mayo de Santa Fe de Ronald Reagan, el primer dinero de la CIA financiando a los exiliados nicaragüenses en Miami, la permanencia del bloqueo de EE.UU. a Cuba y el asedio económico al nuevo gobierno que había derrotado a otra dictadura en la isla de Granada, alarmarían igualmente al recién estrenado gobierno sandinista ${ }^{2}$.

La mutua desconfianza se hizo visible rápidamente y Nicaragua empezó a prepararse para enfrentar un previsible ataque norteamericano y una contrarrevolución. La confirmación posterior de que dicha contrarrevolución, alentada por EE.UU., tuviera lugar y desembocara en una guerra abierta, condicionaría en gran medida la actuación del gobierno sandinista en los diez años siguientes ${ }^{3}$.

No existe duda alguna de que la guerra fue determinante en la marcha de los acontecimientos y en la imposibilidad de implantar o completar los proyectos de la revolución. Sin embargo, no lo fue menos la trayectoria seguida por el FSLN que fue alejando a las fuerzas que había aglutinado para derrotar a la dictadura y al que abandonaron relevantes figuras que habían sido claves para alcanzar el triunfo.

Sin renunciar a sus aspiraciones a largo plazo, los sandinistas mantuvieron formalmente su primer programa: pluralismo político, economía mixta y no alineamiento, conscientes de la coyuntura en que vivían. Era imprescindible continuar con sus excelentes relaciones internacionales y, por ello, dieron a conocer ese programa a gobiernos social-demócratas y social-cristianos, como México,

${ }^{1}$ El 19 de marzo de 1980 ya se habían firmado ocho acuerdos entre la primera delegación de la República de Nicaragua con el Gobierno y el Partido Comunista de la Unión Soviética. Dicha delegación estaba compuesta por Moisés Hassan, miembro de la Junta de Gobierno (JGRN); Tomás Borge, ministro del Interior, Humberto Ortega, ministro de Defensa, y Ricardo Wheelock Román, el embajador nicaragüense en Moscú, recién llegado a la URSS.

${ }^{2}$ El 13 de marzo de 1979, el movimiento de oposición de Maurice Bishop, derrocó la dictadura gobernante en la isla de Granada. Poco después, EE.UU. declararía un bloqueo económico y financiero hasta protagonizar la invasión directa a la isla que tendría lugar el 25 de octubre de 1983.

${ }^{3}$ La conocida como «Guerra de la Contra» se nutrió de los sectores del interior del país opuestos al nuevo gobierno -ex-guardias nacionales y campesinado desafecto sobre todo- que estuvieron muy pronto respaldados por la Administración Reagan a través de la CIA. 
Costa Rica, Venezuela y Panamá, antes incluso que a los gobiernos comunistas. Pero, junto a ello, su convencimiento de las bondades del modelo socialista, llevó al FSLN a diseñar unas instituciones que lo apuntalaran, le aseguraran su capacidad de maniobra y su permanencia en el poder. Algo que EE.UU. interpretó como un desafío inasumible y que tuvo un altísimo coste para Nicaragua.

El Frente Sandinista de Liberación Nacional (FSLN), de movimiento REVOLUCIONARIO A PARTIDO POLÍTICO GOBERNANTE

Con un organigrama piramidal y un funcionamiento basado en el «centralismo democrático», tras el triunfo de la revolución sandinista, el FSLN tuvo que emprender la tarea de gobernar el país.

Algunas opiniones sostienen que nunca logró desarrollarse como un verdadero partido político porque no dejó de ser un movimiento político-militar, una organización guerrillera que había tomado el poder por las armas. Después, «o por falta de tiempo, o de una decidida voluntad de construir una verdadera organización política, terminó sirviéndose de estilos muy poco democráticos» ${ }^{4}$. Paralelamente, hay autores que afirman que sí se dio un proceso de conversión en partido político a lo largo de una evolución interesante y novedosa, que haría posible que, en noviembre de 1981, el gobierno presentara un proyecto de Ley que definía a los partidos únicamente como «grupos de nicaragüenses con ideas políticas compartidas para participar en la administración pública» $\rangle^{5}$. En consecuencia, los partidos vencedores en las elecciones co-gobernarían con el FSLN, pero tendrían que reconocerlo como vanguardia aceptando que tuviera el control del Estado. Sin embargo, la llegada de Ronald Reagan al poder en EE.UU. y su ayuda, a través de la CIA, a los sectores nicaragüenses disconformes con la revolución -la ex-Guardia Nacional y los grupos que se le unieron desengañados de la reforma agraria o de las formas autoritarias pronto emprendidas por el los principales miembros del FSLN- provocaría el comienzo de la «Guerra de la Contra» que paralizó un año la actividad parlamentaria. Después, y tras importantes acuerdos con la oposición, en la Asamblea de agosto de 1983 los partidos se definieron ya como «organiza-

${ }^{4}$ Núñez Escorcia, 2000. Vilma Núñez Escorcia, abogada especialista en Derecho Penal y Derechos Humanos, fue una decidida antisomocista, encarcelada en 1979. Aún estaba presa cuando el gobierno revolucionario -todavía en Costa Rica- la nombró Vicepresidenta de la Corte Suprema de Justicia poco antes del triunfo de la revolución.

${ }^{5}$ Borrador de la Ley de Partidos Políticos de febrero de 1982, citada por Close, D., 1988: 123-124. 
ciones que competían por el poder y control del Estado», lo que hizo decir a Shelley A. Mc Connell:

En un giro asombroso, el FSLN dejó de lado el modelo de democracia participativa, basada en las organizaciones de masas, para favorecer un modelo liberal representativo de democracia, basado en los partidos políticos ${ }^{6}$.

Aún así, las críticas con referencia a los comportamientos no democráticos en el FSLN permanecieron y siempre fueron refutadas con el argumento de las prioridades que imponía la guerra. En cualquier caso, el nuevo partido político

\section{CuAdro i. ORganización DEL FSLN}

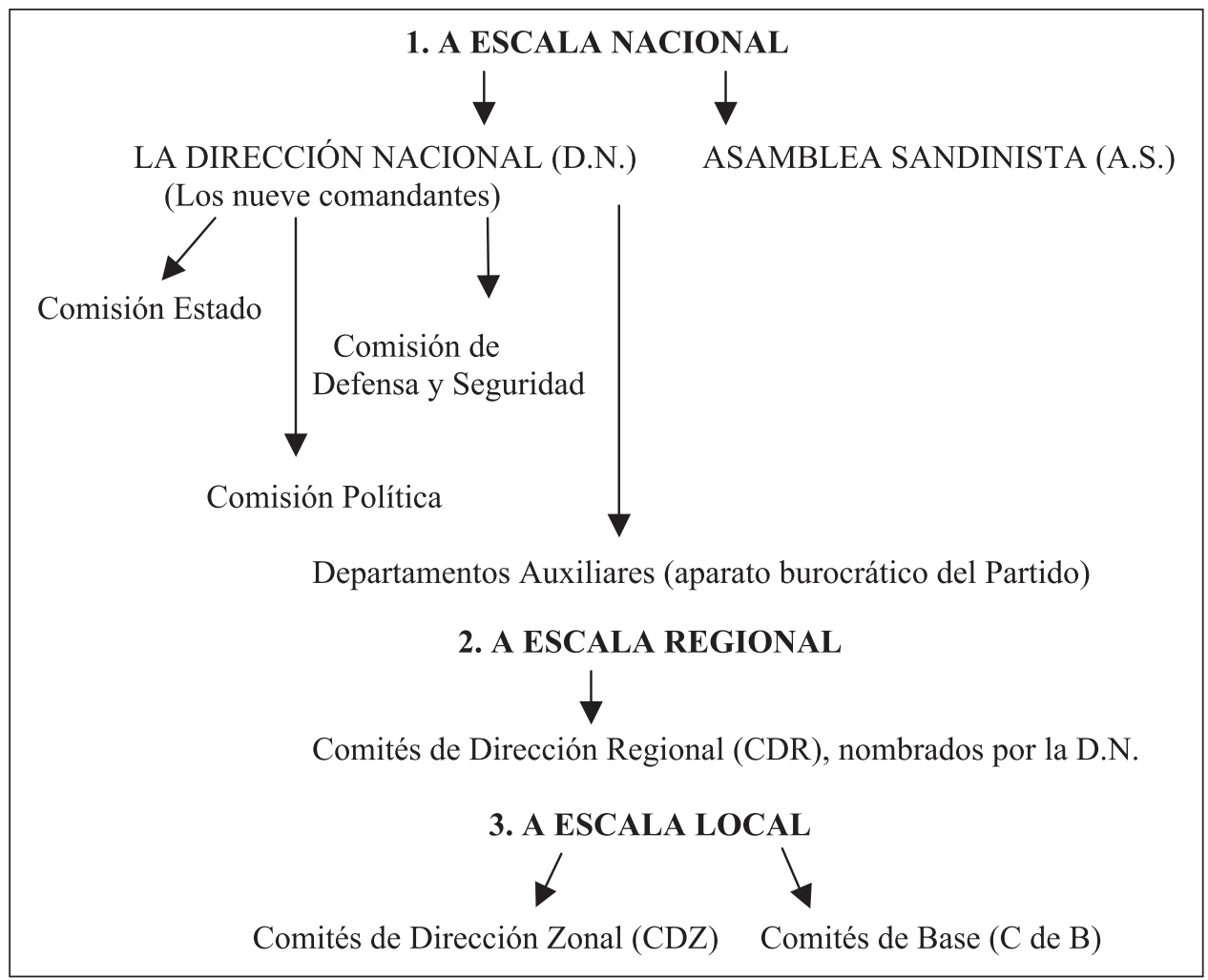

Fuente: elaboración propia a partir de Gilbert, Dennis, 1988.

${ }^{6}$ Mc Connell, 2009: 170. 
agrupó a sus cuadros en cuatro planos diferentes: el primero de ellos, y más importante, a escala nacional, estuvo integrado por la Dirección Nacional y la Asamblea Sandinista.

Los otros tres planos -las escalas regional, zonal y de organizaciones de base- se gestionaban por el resto de la militancia que se repartía las responsabilidades con sus correspondientes órganos en cada uno de los estamentos.

\section{La Dirección Nacional}

Fue el órgano máximo de poder denominado inicialmente «Dirección Nacional Conjunta», y abreviado más adelante como «Dirección Nacional». Constituida en marzo de 1979, fue realmente un reducto de la clandestinidad conformado cuando se produjo en Panamá la unión «formal» de las tres tendencias del FSLN ${ }^{7}$. Dichas tendencias habían surgido en la segunda mitad de la década de 1970 y provenían de las ramas que se desgajaron del primer núcleo disidente que había optado por la montaña, bajo el modelo del «foquismo», heredado de Cuba: la «Guerra Popular Prolongada»(GPP). Ésta, la primera expresión de los fundadores del movimiento, consideró durante mucho tiempo intrusos tanto a los primeros secesionistas, los que se denominaron tendencia proletaria (T.P.), como a los posteriores, de la «tendencia tercerista»o «Insurreccional» (T.I.), llamada así por haber optado por la estrategia de la insurrección.

La mayoría de miembros de estos dos últimos grupos habían estado en el exilio y lo estaban todavía en vísperas del triunfo de la revolución. Fue difícil para la GPP aceptarlos como iguales, lo que no tuvo discusión después de la derrota somocista, porque todos tuvieron que admitir que la estrategia insurreccional había triunfado. A ello se añadió que el FSLN era una fuerza guerrillera sin experiencia como partido político, a la que era imprescindible constituirse en un poder unido y fuerte si realmente deseaba tener continuidad.

La composición de la Dirección Nacional, por ello, tuvo que ser paritaria y quedó integrada por nueve miembros -los nueve comandantes-, tres por cada tendencia: por la GPP, Henry Ruíz, Tomás Borge y Bayardo Arce; por la Tendencia Proletaria (T.P.), Jaime Wheelock, Luis Carrión y Carlos Núñez y, por la Tendencia Tercerista o Insurreccional (T.I.), Humberto Ortega, Daniel Ortega y Víctor M. Tirado.

${ }^{7}$ El término «formal» empleado aquí para calificar la unión de las tendencias alude al frágil carácter que esa unión tuvo siempre y que fue realmente motivada porque Fidel Castro advirtió que no iba a ofrecer ninguna ayuda mientras no fueran un solo movimiento. Las reticencias existieron siempre $y$, en no pocas ocasiones, fueron fuente de problemas. 
Ésa fue la única fórmula que aceptaron todos, sin diferenciar a quienes hubieran arriesgado más, o luchado durante más tiempo, o permanecido en el exilio o en el interior, o se consideraban con más o menos méritos. Las discusiones por esos motivos habían sido arduas y recurrentes y con la paridad intentaron zanjar las viejas suspicacias y acusaciones de antaño, aunque nunca se logró del todo. La unidad forzada de las tres tendencias tendría consecuencias negativas porque se fue generando una distribución competitiva del poder por sectores, que todavía empeoraría cuando -por causa de la guerra- el mayor peso fue recayendo en el sector militar ${ }^{8}$.

De la Dirección Nacional dependían directamente cuatro comisiones: Comisión de Estado, Comisión Política, Comisión de Política Exterior o de Defensa y Seguridad. Las dos últimas fueron organizadas como apoyo a la Dirección Nacional para el análisis de los asuntos internacionales y de defensa. Una de ellas, la Comisión de Estado, era el lugar donde se discutían los asuntos más importantes y sus resoluciones se presentaban a la Dirección Nacional que, por lo general, aprobaba. Después, la Dirección Nacional podía llevar esos temas a la Asamblea o no hacerlo, a su criterio. Dicho funcionamiento puede servir de ejemplo de los vasos comunicantes que existieron entre Partido y Estado. Aunque la comisión era una agrupación creada con el objetivo de velar por la gestión y la vida del partido, de ella saldría, por ejemplo, el «Comité Jurídico», que fue el organismo que se ocuparía de todos los asuntos jurídicos nacionales ${ }^{9}$.

Con el tiempo, la importancia de la Dirección Nacional fue de primer orden porque realmente el FSLN se fue convirtiendo en un verdadero Partido-Estado sobre el que se ha debatido si fue más seguidor de los «modelos» de Cuba o de la URSS, o del PRI mexicano ${ }^{10}$. La duda está fundamentada en que el FSLN se asemejaba al PRI en que ambos competían con otros partidos, lo que no ocurría en Cuba ni en la URSS; sin embargo, la diferencia estribaba en que, mientras el PRI era un partido al que se acusaba con frecuencia de fraude, el FSLN estaba tan confiado en su popularidad que ni siquiera se planteó la necesidad de algo similar y acudió a dos elecciones -en 1984 y 1990- con la conciencia y seguridad de ser el partido ganador.

8 Circular Ejecutiva de la Dirección Nacional del Frente Sandinista de Liberación Nacional (FSLN) a la militancia sandinista en general, 22-3-1979, Archivo privado de Ernesto Castillo Martínez, Managua (en adelante, AECM). Ernesto Castillo fue integrante del «Grupo de los Doce» antes del triunfo de la revolución, Procurador General de Justicia de 1979 a 1985 y Embajador de Nicaragua en la URSS de 1985 a 1990. AECM (sin clasificar).

Véase para ampliación de datos sobre los nueve comandantes: Christian, 1981: 194-199. Gilbert, 1988: 42-48.

${ }^{9}$ Entrevista de la autora con Ernesto Castillo, Managua, noviembre, 2012.

10 Mc Connell, 2009: 271. 
Por otra parte, aunque los distintos órganos del Estado Revolucionario se perfilaron y definieron, ello no fue óbice para que siempre estuvieran presididos por la Dirección Nacional. Esa cúspide de poder era de una significación ya excesiva en las propias estructuras del partido, pero no tenía ajuste alguno en las de un Estado que pretendiera ser calificado como un «Estado de Derecho». Que dicho sea de paso, tampoco constituía la mayor pretensión política ni era motivo de preocupación en aquellos momentos.

La Dirección Nacional, integrada por quienes habían liderado el triunfo contra la dictadura, mostraba tal currículum histórico como el mayor aval para conformar el órgano máximo de poder. Así se fue situando por encima de la Junta de Gobierno de Reconstrucción Nacional (JGRN), teóricamente el poder ejecutivo; un ejecutivo en el que se mezclaban las funciones del partido preeminente y las del gobierno, dado que varios de sus miembros fueron a la vez ministros en la primera de las tres categorías en que se clasificaron los Ministerios. Tras ella, existía una segunda, en la que participaban los miembros de la Asamblea Sandinista, y en la tercera, todos los demás, los que habían sido sencillamente antisomocistas de la confianza del FSLN.

En consecuencia, la Dirección Nacional, como institución, fue el eje del poder en la década de 1980. Pero los nueve comandantes, como personas que la integraban, representaban mucho más: eran los poseedores de unas biografías en la lucha contra la dictadura admiradas y respetadas por la ciudadanía en general hasta el punto de que les fueron envolviendo en un entorno de superioridad que les distanció cada vez más de los que les habían encumbrado. Se convirtieron en una élite que deliberaba internamente, pero que no hubiera admitido discusiones o críticas desde fuera, de haber existido alguna, lo que tampoco ocurría. Un órgano colegiado donde se debatían intensamente todos los temas antes de tomar una decisión, hasta el punto de que nadie se destacaba de cara al exterior en ningún aspecto, celosos todos de aparecer como un bloque unido. Ese carácter colegiado permaneció durante toda la década, como también la excepcionalidad de su poder desproporcionado en los engranajes del nuevo Estado.

La aceptación de las decisiones de la Dirección Nacional, sin protesta alguna, no era nada extraño porque las organizaciones sindicales, sociales o gremiales tampoco elegían a sus dirigentes. Era la Dirección Nacional la que nombraba a los Secretarios Generales de la Central Sandinista de Trabajadores, de la Salud, de las juventudes y de la Asociación de Mujeres Nicaragüenses Luisa Amanda Espinoza (AMNLAE) ${ }^{11}$. A todos. Se aceptaba una jerarquía muy

11 Esta asociación, que fue una iniciativa del FSLN inicialmente muy valorada, se reveló más tarde manipulada por el Frente y sin verdadera libertad para sus integrantes. De sus disidencias surgieron otras asociaciones feministas. Véanse para mayor detalle: Randall, 1999. Babb, 2012. 
vertical, en base a una filosofía marxista-leninista del poder que la concebía como algo orgánico-ideológico. En palabras del escritor, Sergio Ramírez:

La estructura del poder seguía el modelo de un Bureau Político que tomaba las decisiones, un Comité Central, que era la Asamblea Sandinista, que solo bendecía esas decisiones y la aplicación del centralismo democrático, que terminaba por no ser democrático. Además, durante la guerra no hubo lugar para grandes debates políticos, sino que había nueve personas que 'estaban bendecidas por la divinidad', y que lo que decidían era lo justo y necesario. Y a los demás solo les tocaba obedecer.

El cambio de pensamiento vino después de la derrota electoral de 1990, pero más bien porque, al desaparecer la fuerza de la Dirección Nacional, cada uno buscó su propio cobijo y entonces si empezaron participar y a elegir a sus dirigentes ${ }^{12}$.

Incluso, aunque no se hubiera tomado como modelo el marxista-leninista para el estilo vertical del FSLN, el sandinismo de a pie no tenía motivos para admirar las prácticas tantas veces falseadas durante la dictadura de los Somoza. Y el sentimiento político de entonces -como expresara el citado autor en Adiós Muchachos - era «el deseo de barrer con la historia, porque no se triunfa con las armas para conquistar un poder de corto plazo» ${ }^{13}$.

Pero, si ya en sí era problemática la inserción forzada que la Dirección Nacional ejerció de hecho, su propia estructura complicaba aún más sus relaciones con el resto de los poderes del Estado: los comportamientos verticales y jerárquicos del FSLN herederos de su experiencia clandestina que se vieron fácilmente reforzados por la cultura caudillista tan arraigada en Nicaragua. Como resultado, tanto políticos relevantes del nuevo Estado, como la propia ciudadanía en general, mantuvieron ante la Dirección Nacional una actitud de reconocimiento y de servilismo de los que es sumamente expresiva, como muestra del acatamiento a su autoridad, la máxima popular que se refería a ellos diciendo: «Dirección Nacional, jordene!».

En esa mitificación de la Dirección Nacional tuvo mucho que ver -según diversas opiniones de ex-militantes críticos- el aparataje que se fue creando por influencia de los asesores cubanos: los comandantes se fueron rodeando de un ejército de auxiliares que les procuraban desde artículos tan básicos como la vestimenta hasta los teléfonos de última generación; caprichos de todo lo último del mercado para cubrir sus necesidades materiales, para unos

${ }^{12}$ Entrevista de la autora con Sergio Ramírez, Managua, diciembre 2010. Sergio Ramírez fue integrante del «Grupo de los Doce» en los tiempos inmediatos al triunfo de la revolución, así como de la Junta de Gobierno de Reconstrucción Nacional (JGRN) de 1979 a 1985 y Vicepresidente del Gobierno entre 1985 y 1990.

13 Ramírez, 1998: 226-227. 
dirigentes que, se suponía, no debían estar interesados en obtener privilegios. Sin embargo, se acostumbraron rápidamente a vivir muy por encima de sus conciudadanos y todos los datos apuntan a que pronto se aislaron de ellos. A este respecto, algunos altos cargos de entonces recuerdan que, tras una visita de Olof Palme a Nicaragua después del triunfo de la revolución, cuando se encontró de regreso en Suecia, les escribió y les advirtió que se estaban alejando del pueblo.

Si la aparición de la Dirección Nacional había obedecido, en su momento, al reparto de poder entre las tendencias del FSLN, su mantenimiento se debió a la creencia de que era necesaria la vanguardia de un partido hegemónico que consolidara y orientara la revolución. Cierto es que, junto a ese convencimiento, también persiguieron el ideal de una «democracia económica»: que garantizara las necesidades básicas de la población y no se corriera el riesgo de colocar al Estado en un lugar de sometimiento al mercado. Pero, ante todo, el FSLN se vio impelido a prolongar su carácter político-militar, tanto por la contrarrevolución como por sus prácticas de clandestinidad de las que apenas pudo desprenderse ${ }^{14}$.

Ese mismo carácter político-militar motivó que los dos Ministerios con más poder fueran Defensa e Interior y las personas más poderosas, las cabezas de esos Ministerios: Humberto Ortega y Tomás Borge, respectivamente. Y ni siquiera entre ellos hubo paridad: la influencia de Humberto Ortega superó pronto a la de Tomás Borge, porque la fortaleza del FSLN continuaba estando en las armas y, por ende, en el ejército. Por ello, en el contexto de un país en guerra después de la brutal dictadura y sus miles de muertos, se magnificó aún más todo lo militar. Una última razón fue la imitación del sistema soviético, donde los organismos de Interior e Inteligencia se subordinaban a los de Defensa.

Para el ejercicio del control en las diferentes áreas, la poderosa Dirección Nacional del FSLN conformó su organigrama con siete departamentos auxiliares: Departamento de Relaciones Internacionales (DRI), Departamento de Agitación y Propaganda (DAP), Departamento de Educación Política (DEP), Departamento de Organización de Masas (DORMA), Departamento de Finanzas (DEFIN), Secretaría de Asuntos Generales (SAG) y el Instituto de Estudios del Sandinismo (IES).

${ }^{14}$ Según testimonios de ex-militantes del FSLN, la permanencia de esa clandestinidad se reflejaba en aspectos tan banales y cotidianos, como la costumbre de no entregarles recibos por el pago de las cuotas y de exigir el dinero en efectivo, aún cuando ya era un partido legal y formaba parte del Gobierno. Más tarde, se vieron obligados a adecuarse a los nuevos tiempos porque había quejas por ese tipo de comportamientos, pero nunca se eliminaron del todo. 
Al lado de este pesado aparato, la Asamblea Sandinista constituyó por algún tiempo alguna forma de contrapeso, aunque nunca puso en duda las decisiones de la Dirección Nacional, ni tampoco hubiera tenido la opción de promover ningún cambio en las mismas.

\section{La Asamblea Sandinista}

La Asamblea Sandinista fue el órgano colectivo superior del partido y estuvo constituida por los cuadros del FSLN anteriores al triunfo de la revolución, que oscilaron entre 77 y 110 . En su seno se encontraban los principales dirigentes políticos y fue el organismo deliberativo de las cuestiones que la Dirección Nacional deseaba someter a la discusión. Sus miembros eran escuchados, pero carecían de los derechos de voto y de veto al respecto de las cuestiones que se les planteaban; fue un instrumento más de la Dirección Nacional, cuyos integrantes se ocuparon fundamentalmente de la administración del Estado.

En poco tiempo la Asamblea Sandinista perdió funcionalidad por el ascenso ininterrumpido de la Dirección Nacional. Pasó a quedar solo como un instrumento de ratificación de las decisiones de aquella, lo que se aceptaba sin discusión porque se sustentaba en el «centralismo democrático», con el que estaban de acuerdo también los cuadros intermedios del FSLN.

A escala regional, funcionaban los «Comités de Organización Regiona»1 (CDR) que fueron 14 hasta 1982. Desde esa fecha, por imperativos de la guerra, cambio la división administrativa y el Estado se organizó en seis regiones y tres zonas especiales. A escala local, el reflejo del Frente estaba en los «Comités de Dirección Zonal» (CDZ), presididos por un secretario político $\mathrm{y}$, finalmente, en el último escalón, los «Comités de Base» $(\mathrm{CdB})$, integrados por un máximo de 20 personas, de entre las cuales, según los estatutos, debía haber al menos una militante del FSLN ${ }^{15}$. No obstante, en la práctica, todos sus miembros eran militantes, dado que -también según los estatutos- «su objeto era asegurar la presencia, acción y movilización política del FSLN».

\section{EL PROCESO HACIA LA HEGEMONÍA DEL FSLN}

El ascenso del FSLN no se puede comprender si no se tiene en cuenta que pocos días antes de la entrada triunfal del 20 de julio de 1979 todavía

15 Marti i Puig y Close, 2009: 36-37. 
no se tenia una idea clara sobre cómo se podría establecer la relación futura del Frente con los sectores económicos, representados en la empresa privada, ni con los tradicionales políticos, representados en el Frente Amplio Opositor (FAO). Todos habían impulsado la insurrección en su etapa final y decisiva y por el empuje de todos había caído la dictadura. Pero entre los días 16 y el 19 de julio hubo novedades, no siempre suficientemente valoradas, que cambiaron la historia de Nicaragua. Ni el FSLN había calculado realmente la imagen de fuerza y seguridad que daba hacia fuera, ni los elementos somocistas que agonizaban eran tan resistentes como habían creído sus simpatizantes e, incluso, sus opositores.

Ante la sorpresa generalizada, cuando se estaba tratando de lograr un complicado equilibrio de fuerzas entre la antigua Guardia Nacional y los nuevos cuadros de la seguridad sandinista, se produjo la debacle y huida inesperada de aquella y el Frente fue consciente entonces de que tenía todo el poder. Como consecuencia, se dio un cambio de estrategia y se tomó la decisión de adelantar el proceso hacia la meta idealizada de una sociedad socialista. Se desplomaron las viejas estructuras y se produjo la salida del efímero presidente Francisco Urcuyo Maliaños ${ }^{16}$.

En esas circunstancias, el FSLN no tuvo tiempo de incorporar una nueva legislación, ni medidas más radicales, ni acordes con su modelo de Estado. Lo prioritario en esos momentos fue definir las relaciones del sandinismo con la burguesía y, con ese fin, se convocó la primera reunión de los viejos cuadros militantes en la primera asamblea sandinista. Solo eran 78 miembros, aquellos a los que el triunfo de la revolución había permitido dar un salto cualitativo y coronar su proceso de liderazgo. En tres días había culminado un proceso de diez años. El país entero había contribuido a la derrota de la dictadura, pero se estaba otorgando el poder de tomar las decisiones políticas solo a 78 personas. Así comenzó la concentración de poder del FSLN.

No obstante ese inesperado golpe de suerte para el FSLN, persistían dos problemas insoslayables: la falta de unidad real de las tres tendencias del Frente y la imposibilidad de prescindir de los sectores económicos que habían apoyado al nuevo gobierno. Por esos motivos, sin renunciar a los objetivos finales, el Frente decidió optar por una etapa de transición en la que se decidió

${ }^{16}$ Francisco Urcuyo Maliaños fue el político que tomó posesión de la presidencia de Nicaragua, de forma transitoria, a la salida del país de Anastasio Somoza Debayle. El acuerdo con EE.UU. era traspasar el poder a la Junta de Gobierno (JGRN), pero, sorpresivamente, Urcuyo se negó a ese traspaso y anunció que no dejaría su puesto hasta las elecciones de 1981. Poco después, cuando el FSLN entró triunfante en Managua, Urcuyo Maliaños tuvo que abandonar el país. 
conservar algunas estructuras viejas de difícil recomposición, como lo eran la Justicia y la representación asamblearia. Sin embargo, esa transición solo duraría unos meses, porque muy pronto optaron dejar fuera a la gran mayoría de sus aliados. Cada vez el sandinismo necesitó menos la participación de los partidos tradicionales, los pequeños grupos de izquierda y sectores privados, y se propuso separar de las instituciones a la alta burguesía caficultora y ganadera por temor a las iniciativas que pudiera plantear. La forma de hacerlo fue la redacción de un documento que se presentó en la Primera Asamblea de Cuadros del FSLN, entre el 21 y el 23 de septiembre de 1979, después conocida como «Asamblea de las 72 horas».

\section{La Asamblea de las 72 horas: la radicalización de la revolución y el camino hacia la exclusión de los no sandinistas}

Fue éste un documento de capital importancia en el que se declaraba que el objetivo interno del FSLN era llegar a una sociedad socialista, continuar la alianza con la burguesía el menor tiempo posible y consolidarse como un partido marxista-leninista ${ }^{17}$. Asimismo se señalaba que, de cara al exterior, se debía seguir manteniendo el programa dado a conocer el 9 de junio de 1979 y diseñado tiempo atrás por el «Grupo de los Doce» ${ }^{18}$. Dicho programa fue

17 Esa definición no negaba un fuerte componente cristiano y nacionalista que, en Nicaragua, se conocía y valoraba. Gran parte de los más prestigiosos líderes del sandinismo se integraron en él por convicciones cristianas y Sandino era considerado el referente nacionalista indiscutido.

${ }^{18}$ Fue un grupo de personas de reconocido prestigio en Nicaragua y que no militaban, al menos explícitamente, en ningún partido político. Se constituyeron en 1977 y, al apoyar al FSLN, le proporcionaron una imagen respetable y digna de confianza ante la burguesía o sectores empresariales. Fueron los siguientes: Sergio Ramírez, escritor conocido internacionalmente, miembro no público del FSLN y coordinador del grupo; Miguel D’Escoto, religioso católico que trabajaba para la orden Maryknoll en los EE.UU. y también era miembro secreto del FSLN; Fernando Cardenal, jesuita y ex vice-Rector de la Universidad Centroamericana a cargo de su orden; Joaquín Cuadra Chamorro, conservador y abogado del grupo del Banco de América, Grupo Pellas.; Emilio Baltodano Pallais, empresario, dueño de fincas de café y socio y gerente de la compañía productora de café más importante de Nicaragua, el Café Soluble Presto; Felipe Mántica, dueño de la cadena de supermercados más grande del país y de unos grandes almacenes vinculados con el grupo del Banco de América; Arturo Cruz, banquero y alto funcionario del Banco Interamericano de Desarrollo de Washington; Carlos Tünnermann, ex Rector de la UNAN y residente en México; Ricardo Coronel Kautz, ingeniero agrónomo y uno de los técnicos más importantes del Ingenio San Antonio, propiedad de la familia Pellas, la más adinerada del país; Ernesto Castillo, abogado, ex profesor de la UCA y residente en Costa Rica desde el año anterior; Carlos Gutiérrez, dentista residente en México y protector de los 
básicamente el mismo que se mantendría en adelante y se cimentaba en tres principios básicos: economía mixta, pluralismo político y No Alineamiento.

No era la primera vez que se definía en ese sentido el FSLN, pues ya en 1969, el más mítico de sus fundadores, Carlos Fonseca, había declarado: «el magno objetivo es la revolución socialista» ${ }^{19}$. Ello, sin embargo, no obsta para que entre los simpatizantes y seguidores del FSLN se diera una notable mezcolanza de procedencias ideológicas, tanto marxistas, como cristianas, como nacionalistas o antiimperialistas. Pero fue fácil acordar entre los militantes una definición socialista frente a la experiencia vivida con los Somoza, paradigma de una dictadura protegida por EE.UU., el máximo exponente del capitalismo. De hecho, en pleno contexto de la Guerra Fría, el socialismo no fue una utopía atractiva únicamente para la izquierda Latinoamericana -en pos de un mundo más justo y solidario como contrapartida a las numerosas dictaduras pro-norteamericanas de la década de 1970-, sino que era también la alternativa contemplada por la izquierda europea. Así pues, el limitado número de componentes de la «Asamblea de las 72 Horas» declararon su aspiración de lograr un modelo socialista para el nuevo Estado.

Hasta ese momento, se había ofrecido una pantalla democrática, aunque se creyera firmemente en la necesidad de una vanguardia que liderara la revolución. Pero ahora ya, el FSLN se erigía en cabeza de las fuerzas y partidos anti-somocistas y se aseguraba de ser quien ejerciera en adelante el papel rector de todo el proceso. Muchos de los aliados y simpatizantes de dentro y fuera de Nicaragua se escandalizaron al conocer el documento -que era secreto, pero se filtró- y eso fue un nuevo acicate para que los partidos y grupos de derechas se unieran más y creciera la desconfianza en los objetivos de la revolución.

En el documento se distinguía que el «dominio imperialista de la fuerza -por la vía de la Guardia Nacional- había sido derrotado», pero el «dominio imperialista de las finanzas» permanecía y ligaba a Nicaragua al esquema financiero internacional "productor de deudas eternas más que externas»; los principales defensores de dicho esquema financiero serían las clases pudientes con intereses económicos, los que el FSLN llamaba «burgueses vendepatrias», de los que habría que desprenderse. Del mismo modo que habría que apartar a la «ultraizquierda», a aquellos que abogaban por una revolución sin ninguna transición, ni siquiera aparente, de alianzas con las clases medias y altas. Tras

exiliados nicaragüenses allí, y Casimiro Sotelo, arquitecto residente en California y principal cabeza de la solidaridad con el FSLN en San Francisco, California. Fueron una pieza clave para la expansión de los apoyos al FSLN en su lucha contra los Somoza. Nolan, 1986: 123.

19 Fonseca, 1985: 167. 
ese somero análisis, el FSLN sintetizaba en una serie de puntos los objetivos a conseguir:

1. Aislar de los sectores democráticos a la burguesía vendepatria, igual que a la ultraizquierda y a todo residuo del somocismo y organizar a las fuerzas motrices de la Revolución colocándolas bajo el FSLN.

2. Situar la economía estatal como el eje de la economía nacional y garantizar la efectiva participación de las organizaciones de masas.

3. Perseguir en la política internacional el refrendo de los países, gobiernos, y organizaciones amigas y neutralizar a los sectores reaccionarios.

4. Desarrollar todos los esfuerzos para aglutinar alrededor de la vanguardia, la unidad de las masas revolucionarias.

5. Construir, fortalecer, y educar al Ejército Popular Sandinista, cultivando su fidelidad hacia su pueblo y su Revolución encabezada por el FSLN.

6. Emprender la tarea de reorganizar al FSLN y transformarlo en el partido de la Revolución Popular Sandinista, incluyendo el fortalecimiento de la Dirección Nacional, la eliminación orgánica de las tendencias dentro del FSLN, la fijación de la estructura vertical del partido y el anuncio del Servicio Militar Obligatorio $^{20}$.

El documento de la «Asamblea de las 72 horas» marcó el inicio de un cambió de rumbo por los acuerdos que se lograron para construir los instrumentos necesarios que garantizaran la preeminencia del FSLN y aceleraran el proceso revolucionario. En sus sesiones se acordó el mantenimiento de las leyes de emergencia, de los Tribunales Especiales y de las Leyes Económicas de Orden Público durante más tiempo del previsto anteriormente. Como se evocaba en un Blog ciudadano en el treinta aniversario del triunfo de la revolución:

(...) La Vanguardia del FSLN, para el derrocamiento de Somoza, había utilizado a todos los actores sociales, abarcando desde la burguesía antisomocista hasta el lumpen de cuneta de barrio. Con todos estaba en deuda, pero no a todos les cumplió ${ }^{21}$.

Se hizo patente la decisión del partido de consolidar y conservar el poder ante la eventualidad de una alianza de la alta burguesía nacional con los intere-

20 Peñalba, Rodrigo, Blog de las 72 horas, 20-7-2009, http://www.penalba.info/blog/2009/07/ 20/las-72-horas (Fecha de verificación: 15 de septiembre de 2015).

${ }^{21} \mathrm{http}: / /$ emilapersola.blogspot.com (Fecha de verificación: 15 de septiembre de 2015). 
ses estadounidenses encaminada a organizar una reacción contrarrevolucionaria. Y se mencionó ya la intención de instituir un servicio militar obligatorio, que tantos problemas ocasionaría más adelante ${ }^{22}$.

\section{Primeras dificultades y síntomas del déficit democrático}

Como consecuencia del camino emprendido por el FSLN, se intensificaron muy pronto sus discrepancias con las distintas agrupaciones o partidos políticos, antes aliados. Solo se había empezado a concretar un bosquejo de Consejo de Estado -el poder legislativo- pluralista en ese momento, cuando los sandinistas encontraron más justificado que nunca iniciar el apuntalamiento de su modelo. Tuvieron la certeza de que su anti-imperialismo, obviamente entendido como antiamericanismo, era la respuesta adecuada al comienzo de la agresión que fue la «Guerra de la Contra». Para entonces, el núcleo duro del partido ya había decidido unánimemente que el modelo de Estado que la revolución debía perseguir -al menos como declaración oficial- era el marxista-leninista.

Ante la amenaza de la guerra, el pueblo se unió de nuevo al Frente incondicionalmente, pero la interpretación de esa solidaridad y confianza fue, tal vez, su primer error: el FSLN identificó el apoyo de la ciudadanía para combatir la agresión, con el apoyo a su concepción ideológica, que la inmensa mayoría ni entendía ni tenía entre sus prioridades. El segundo error, de cara a EE.UU., fue la decisión y anuncio de no convocar elecciones hasta 1984.

En muchos aspectos, toda la actuación del Frente fue un arriesgado ensayo lleno de urgencias por la inminente guerra, además de los problemas sobrevenidos por su inexperiencia de gobierno, ya que nunca hubo en Nicaragua «zonas liberadas» como las que tuvo la guerrilla salvadoreña del Frente Farabundo Martí para la Liberación Nacional (FMLN) ${ }^{23}$. Por otra parte, esa inexperiencia, unida al deseo irrenunciable de protagonismo pudo deberse, en cierto modo, a la juventud de sus más notables elementos. La vanguardia del FSLN -procedente de estudiantes de secundaria y primeros años de universidad- tenía en 1979 una edad media de 20 a 22 años. Una juventud que se había investido de una imagen de arrojo, heroísmo y temeridad en la lucha contra la dictadura, pero que se podía encontrar con dificultades en la nueva situación en la que se debía organizar para dirigir un país con moderación,

${ }^{22}$ Asamblea de Cuadros Rigoberto López Pérez, 21, 22 y 23 de septiembre 1979. Análisis de la coyuntura y tareas de la revolución popular sandinista, AECM, (sin clasificar).

23 Marti i Puig y Close, 2009: 71. 
equilibrio y eficacia; para conformar un gobierno para los tiempos de paz, estable y a largo plazo.

No fue una razón menor que la cúpula del FSLN tuviera la idea fija de no arriesgarse a quedar diluida entre los nuevos órganos de gobierno, ni a poner en marcha un proyecto en el que no se sintieran satisfechos todos los líderes de primera línea del movimiento; aquel núcleo duro que también suscribía otra de las consignas marxista-leninistas y que rezaba: «toda revolución genera una contrarrevolución». Con tal bagaje político-ideológico, desde los inicios del nuevo régimen tuvieron la seguridad de que EE.UU. les atacaría y se prepararon para ello.

En definitiva, se dio un componente muy notable de improvisación y desconocimiento de lo que suponía el paso de ser oposición a ser gobierno; de acomodar una estrategia de guerra a una estrategia de paz. Y ello se sumó al hecho indiscutible de que en el proceso de lucha para derrotar al somocismo, el Frente había logrado un apoyo popular total en los tiempos ya cercanos al triunfo. Ello proporcionó al movimiento la certeza de una legitimidad sobrevenida por la frase tal vez más aceptada: «la revolución es fuente de derecho». Por último, se encontraron con un reto de proporciones gigantescas al tener que administrar un país destrozado por la guerra y descapitalizado. Como dijo una guerrillera histórica, «cuando llegamos al triunfo, en el Banco Nacional había 300 dólares $»^{24}$.

Todo lo anterior les animó a optar por no constituir un gobierno provisional que redactara una constitución y que emprendiera un proceso electoral, pese a que fue uno de los consejos que les había dado el propio Fidel Castro, al que tanto admiraban ${ }^{25}$. Esa opción, tal vez hubiera tranquilizado a EE.UU. y hubiera alejado al nuevo gobierno de la guerra y del peligro de una invasión. Pero no se hizo así, y se explicó por algunos como resultado de un celo intenso de parte de los dirigentes por poner en práctica un programa radical a favor de los pobres. Para otros, como la periodista Sofía Montenegro, sin embargo, fue debido a la ausencia de pensamiento democrático entre las filas del FSLN. Según su percepción, fue negativo desde el principio el enorme poder que acumuló el Frente. En su opinión, con el grado de consenso que hubo en la revolución y la expectativa libertaria que tenía la gente, perfectamente se hubiera podido establecer un modelo menos sesgado y dogmático del que se instituyó y hubiera empezado enseguida la desmilitarización. Pero el esquema de pensamiento era tan fuerte y de-

\footnotetext{
${ }^{24}$ Entrevista de la autora con Rosario Antúnez, Estelí, Nicaragua, 2010.

${ }^{25}$ Afirmación repetida por diversos líderes políticos de primera línea que insistieron en el pragmatismo de Fidel Castro y sus consejos coyunturales para Nicaragua.
} 
terminista que precipitó una serie de errores que se fueron encadenando y reforzando con la obsesión de que «iban a llegar los gringos»y, con ellos, la contrarrevolución, lo que hizo perder una oportunidad histórica extraordinaria. A ese proceso, ella añadía:

Yo no creo que hubiera personas que tuvieran un pensamiento democrático dentro del Frente. Si hubiera habido una mayor dosis de valores democráticos entre sus gentes, seguramente esos valores hubieran atemperado las tendencias militaristas y dogmáticas, intolerantes y sectarias. A la derecha no se le dio más espacio y yo pienso que hubiera estado llamada a aportar esos elementos de pluralidad, de tolerancia, de crecimiento en el respeto democrático. Pero antes del año ya se descolgó la derecha y eso alienó a muchísima gente. El Frente tendió a polarizar en lugar de evitar esa polarización ${ }^{26}$.

No obstante, la valoración de la democracia y separación de poderes no estuvo ausente solo de las filas sandinistas. La convocatoria de elecciones fue un asunto al que no prestaron excesivo interés ninguno de los miembros de la Junta de Gobierno. El retraso de su convocatoria no suscitó una gran oposición, aunque el Consejo de Estado (legislativo) fuera abandonado por el conjunto de partidos que constituía el «Movimiento Pueblo Unido» (MPU). Gilles Bataillón apunta una idea sugerente al respecto al recordar que la cultura nicaragüense, con su legado de jerarquías sociales, admiraba a los grupos sociales que consideraba con capacidad para gobernar a los demás. De una parte, «los respetados económica y socialmente», los poderosos o brillantes profesionales de siempre, y de otra, a los sandinistas porque eran «los que sabían dirigir a las masas» ${ }^{27}$. Algo similar a lo que en otras latitudes se denominó la intelligentsia, aunque en el caso nicaragüense, no fuera ya referida exclusivamente a una élite intelectual, sino social de diversa índole. El FSLN, con su prestigio e influencia sobre los sectores populares y los representantes de la burguesía, con el manejo de sus redes clientelares, aseguraba el orden social y ello invalidaba en gran medida la necesidad de las elecciones. Lo que sí molestó realmente a la burguesía fue que el Frente no terminaba de concretar cómo habría de funcionar la economía del sector privado. En consecuencia, el Consejo Superior de la Empresa Privada (COSEP) lo empezó a denunciar

${ }^{26}$ Entrevista de la autora con Sofía Montenegro, Managua, noviembre de 2010. Sofía Montenegro destacó como feminista activa en toda Latinoamérica y, como periodista, estuvo a cargo de la página editorial de Barricada desde 1985 hasta 1989, en que inauguró la publicación de la revista semanal Gente, dentro del mismo diario. Fue fundadora de la Cátedra de Género y Comunicación de la Facultad de Comunicación Social de la Universidad Centroamericana y es en la actualidad Directora Ejecutiva en Managua del Centro de Investigación de la Comunicación (CINCO).

${ }^{27}$ Bataillon, 2008: 185 y ss. 
en 1980, acusando a la Junta de Gobierno de Reconstrucción Nacional de establecer un «capitalismo de Estado» ${ }^{28}$.

Los «socios» del FSLN empezaron pronto a tener la sensación de que aquel quería dirigir al resto de los grupos como si se tratara de células suyas y eso ya no lo aceptaron. El «Frente Patriótico»-liberales, socialcristianos, comunistas y nacionalistas- se rompió y con él la opción de atraer a sectores que no estaban con la revolución. Como afirmó Onofre Guevara:

El Frente debió haber contado con el resto de los partidos representados en la Junta de Gobierno, pero no lo hizo. Le pudo más la emoción del triunfo y, mientras los sectores de la derecha eran manejados por los EE.UU. con mucha habilidad, el Frente iba chocándose contra la pared porque quería imponerse en todo y alcanzar el nivel de la revolución cubana de manera artificiosa. Su ideal era hacer otra revolución cubana y eso condujo a lo que pasó porque perdió el sentido de la realidad histórica de Nicaragua. Pudo haber sido una revolución no radical, pero que todavía existiría, que hubiera estado de acuerdo a las realidades económicas y sociales de Nicaragua y no impuesta por el ideal que el Frente tenía de revolución. Pero no se hizo ${ }^{29}$.

Aún con tantos avatares, los primeros tres años después del triunfo de la revolución fueron los de la creación institucional del Estado Revolucionario y en los que el FSLN todavía estuvo avalado por el enorme capital político de la victoria sobre la dictadura. Pero estaba tan convencido de que se había alcanzado el poder fundamentalmente gracias a su lucha y estrategia correcta que reparó tarde en que sus integrantes dejaron de valorar al resto de grupos y partidos que les habían seguido.

\section{EL PROGRAMA Y LAS INSTITUCIONES DEL NUEVO ESTADO REVOLUCIONARIO}

El órgano que representó inicialmente al nuevo poder revolucionario fue la Junta de Gobierno de Reconstrucción Nacional (JGRN). Políticamente, estaba organizado como un régimen de democracia formal, con garantías de respeto a los derechos humanos, sufragio universal y libertad de constitución de partidos políticos y sindicatos de cualquier ideología. En lo referente al modelo económico, la economía mixta se concebía distribuida en tres sectores:

28 Pérez Baltodano, 2003: 599.

29 Entrevista de la autora con Onofre Guevara, Managua, Julio de 2009. Onofre Guevara fue más de 50 años líder obrero sindical, militante del partido socialista primero y del FSLN más tarde. Periodista de Barricada y de El Nuevo Diario, es autor de un libro imprescindible para conocer la historia del movimiento obrero nicaragüense: Guevara, 2007. 
las propiedades estatales, las empresas privadas y las de inversión concertada entre el sector público y el privado.

Después, cuando el 20 de julio de 1979 las columnas guerrilleras hicieron su entrada en Managua, se proclamó el Estatuto Fundamental de la República, que era el que definiría las instituciones del gobierno: un poder ejecutivo que se concretó en la Junta de Gobierno (JGRN) y un poder legislativo en el Consejo de Estado, donde quedaría demostrado el pluralismo político conformado por un amplio conjunto de partidos y agrupaciones: el FSLN, la coalición de izquierdas denominada Frente Patriótico Nacional (FPN), la empresa privada a través del Consejo Superior de la Empresa Privada (COSEP), representantes de la Universidad, la Asociación Nacional del Clero y otra coalición de partidos de centro-derecha que se habían unido en el Frente Amplio Opositor (FAO) ${ }^{30}$.

El nuevo Estado se organizaría en base a dicho Estatuto Fundamental de la República, la Carta Magna que sustituiría a la última Constitución Política somocista de 1974¹. En consecuencia, la JGRN compartiría el poder legislativo con el Consejo de Estado y ostentaría el poder ejecutivo solo de forma transitoria, mientras se elaborara una Ley Electoral. Una vez promulgada la Ley Electoral, la JGRN debería convocar elecciones generales tanto para presidente y vicepresidente, como para elegir a los 90 miembros de una nueva Asamblea Nacional. Todos ellos por un período de seis años.

El esquema inicial encajaba perfectamente en el clásico de cualquier democracia occidental y había sido para el movimiento el mal menor con el que se había logrado la unión interclasista en el interior de Nicaragua. Con él se podía aspirar al logro de solidaridades internacionales, aunque no por ello fue

${ }^{30}$ El Frente Amplio Opositor (FAO) fue una agrupación antisomocista dirigida por el empresario Alfonso Robelo, que era también el jefe del Movimiento Democrático Nicaragüense (MDN) constituido por: UDEL (Movimiento de oposición a Somoza denominado Unión Democrática de Liberación, que logró aunar algunos partidos y sindicatos sin presencia reconocida, como el Partido Liberal Independiente (PLI), Partido Social Cristiano, Movimiento Liberal Constitucionalista, Acción Nacional Conservadora, Partido Socialista Nicaragüense, Central de Trabajadores de Nicaragua y Confederación General de Trabajadores Independiente), Partido Conservador Auténtico, comunistas, socialistas y el Consejo de Unificación Sindical). Además. le apoyaba también el Consejo Superior de la Empresa Privada (COSEP).

${ }^{31}$ La Constitución de 1974 había sido el resultado del pacto entre Anastasio Somoza Debayle y Fernando Agüero Rocha y quedó derogada cuando triunfó la revolución en 1979. Agüero Rocha, el candidato conservador a las elecciones de 1967, estaba apoyado por la Unión Nacional Opositora (UNO) -agrupación de partidos nacida en 1966- y por el Frente Estudiantil Revolucionario (FER), las dos grandes corrientes políticas que había en la Universidad, en protesta contra las aspiraciones de reelección de Anastasio Somoza Debayle. Esgueva Gómez, 2002 o, en síntesis, sin la reproducción de los textos constitucionales; 2003: $1.070-1.080$. 
del gusto de todos los dirigentes del FSLN porque desde el punto de vista de aquellos con mayor empeño en un futuro socialista, la inserción en las reglas «democráticas» fue precipitada. Para ellos, un sistema con Constitución, pluralismo político y tempranas elecciones podía ser una vía que distorsionara y ralentizara el objetivo primordial de la revolución que era terminar con la pobreza y poner en marcha los medios para lograr una mayor justicia económica en el país.

Los primeros documentos del plan de gobierno -del Estatuto Fundamental y de Derechos y Garantías de los Nicaragüenses del 21 de agosto de 1979- siguieron la línea de la pluralidad y se habían pensado y diseñado en pro de una «convivencia necesaria» entre todos los sectores que habían luchado contra la dictadura, mientras el FSLN organizara sus fuerzas, tanto militares como políticas. Un resultado de esa pluralidad fue el decreto de nombramiento de los ministros, del que salió un gobierno plural como nunca antes se había visto en Nicaragua. Ése y otros ejemplos respondían al máximo interés por encontrar formas jurídicas que garantizaran, ante todo, el desmantelamiento de las estructuras somocistas, pero también la reconstrucción de todo lo relativo a la participación de los sectores políticos y sociales no sandinistas. Así se plasmó en la legislación de emergencia, que se suponía de transición hasta que fuera posible consolidar el nuevo proyecto revolucionario ${ }^{32}$. Por ello -como veremos- la primera Junta de Gobierno incluyó a Violeta Barrios de Chamorro y a Alfonso Robelo, no sandinistas, y el Consejo de Estado -el poder legislativo- se organizaría integrando a las diferentes agrupaciones que de una u otra forma habían dado su confianza al FSLN.

\section{El organigrama de gobierno del Estatuto Fundamental}

La nueva organización ponía en funcionamiento una relación entre los órganos del Estado que se ajustaba a las exigencias exteriores de que en Nicaragua se instaurara una democracia y se alejaran los temores de extremismos izquierdistas. En su seno, la Dirección Nacional de los nueve comandantes - que solo era la cúpula de un partido político- no podía tener justificación dentro de ninguno de los tres poderes de la aparente estructura democrática gubernamental.

32 Fueron los denominados «Decretos de Emergencia», casi todos contenidos en el primer volumen de leyes y decretos que se publicaron en la década de 1980. Índice de Leyes y Decretos (1979-2009), Corte Suprema de Justicia y Biblioteca Jurídica de la República de Nicaragua. 
Sin embargo, y pese a las apariencias, en la interrelación entre distintos poderes, de nuevo se hizo evidente que el control del FSLN era una prioridad. Las intromisiones que tuvo que soportar la Junta de Gobierno de Reconstrucción Nacional (JGRN) de parte de la Dirección Nacional fueron continuas durante toda su existencia, en los primeros cinco años de la década de 1980. De ese modo se expresaba la preeminencia del partido sobre el gobierno.

Los otros dos poderes, legislativo y judicial, también estuvieron continuamente mediatizados por la dirección de los nueve comandantes, lo que en realidad desdibujaba la teórica división de poderes que formalmente existía.

La composición de los distintos poderes fue la siguiente:

\section{Cuadro II. Los Órganos de Gobierno según el Estatuto FundAMENTAL DE LA RepÚBlica}

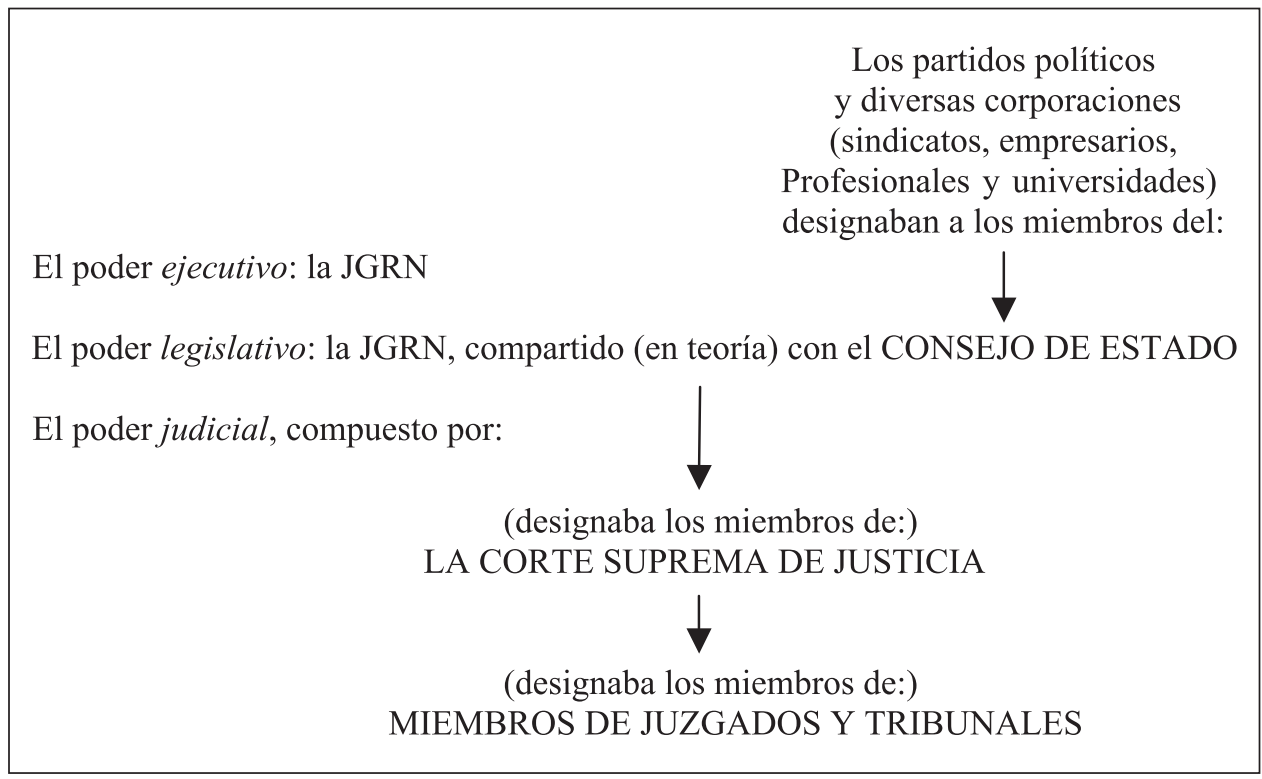

Fuente: elaboración propia.

El poder ejecutivo: la Junta de Gobierno de Reconstrucción Nacional

La Junta de Gobierno había quedado integrada, desde el 18 de junio de 1979, por cinco miembros: Daniel Ortega Saavedra, también de la Dirección Nacional; Sergio Ramírez Mercado, proveniente del «Grupo de los Doce», pero 
secretamente miembro también del FSLN; Moisés Hassan Morales, coordinador del Movimiento Democrático Nicaragüense (MPU), pero ligado al FSLN; Violeta Barrios de Chamorro, esposa del mítico y respetado Pedro Joaquín Chamorro y con dos hijos en el FSLN: Carlos Fernando, de la tendencia proletaria, y Claudia, de la tendencia tercerista; y Alfonso Robelo Callejas, un empresario presidente del Movimiento Democrático Nicaragüense (MDN), en el que había habido habitualmente colaboradores del FSLN.

La composición de la Junta de Gobierno se había establecido en diferentes fases por el jefe del ejército, Humberto Ortega, considerado el estratega del proceso, y había sido la siguiente: antes de la toma del cuartel de San Carlos en octubre de 1977, se había programado que el Presidente del primer gobierno provisional fuera Felipe Mántica ${ }^{33}$. Pero cuando él, más tarde, decidió renunciar, fue evidente en la elección de todos los miembros de la Junta que se dio gran importancia a las consideraciones de partido, a la búsqueda del control del FSLN: así, por consejo de Humberto Ortega, se optó por sustituir a Mántica por Alfonso Robelo tanto por las vinculaciones que tenía con la empresa privada, como por su relación con algunos miembros y colaboradores del FSLN que provenían igualmente del sector privado, como Nicho Marenco, los hermanos Coronel o Alfredo Cesar. Violeta Barrios de Chamorro fue también propuesta por Humberto Ortega, porque estaba avalada por la lucha antisomocista de su esposo y aparecía, en cierto modo, como aglutinadora de la frágil unidad de las tres tendencias del FSLN ${ }^{34}$. Moisés Hassan Morales se integró porque procedía de la tendencia GPP -y antes de la tendencia «Proletaria»- del FSLN y se creyó conveniente contrarrestar la preeminencia del sector «Tercerista». Se celebraron varias sesiones dirigidas por Humberto Ortega, en las que se debatió sobre la elección entre Julio López Campos o Moisés Hassan Morales. Finalmente, se decantaron por el segundo. Daniel Ortega -hermano de Humberto-, por último, tampoco estaba incluido en un primer momento, porque se había pensado que no era conveniente que forma-

${ }^{33}$ Felipe Mántica había sido un elemento clave en el «Grupo de los Doce». Gracias a su prestigio, se estableció en los últimos años prerrevolucionarios la primera comunicación con el presidente de Venezuela, Carlos Andrés Pérez. Propició también que la burguesía nicaragüense modificara su percepción del FSLN como fanáticos comunistas. Mántica, se decepcionó al observar los enfrentamientos internos entre las tendencias del Frente y se retiró. Véase para mayor ampliación: Christian, 1988: 46.

${ }^{34}$ Violeta Barrios era la viuda de Pedro Joaquín Chamorro Cardenal, director del principal diario opositor a la dinastía de los Somoza, La Prensa. Muerto en circunstancias extrañas en enero de 1978, el pueblo culpó siempre a la dictadura y su entierro fue una explosión de indignación popular, realmente el inicio de la insurrección, que yo no cesaría hasta el triunfo final. Su esposo había sido del partido conservador y tenía hijos en el FSLN. 
ra parte de la Junta de Gobierno ningún miembro de la Dirección Nacional. Pero, cuando después se resolvió el espinoso asunto de la organización del ejército, y Humberto Ortega quedó como Jefe del mismo, su nueva influencia le permitió incluir a su hermano en la Junta.

Únicamente conociendo la importancia que tuvo ser el Jefe del ejército se puede valorar la privilegiada posición de Humberto Ortega y su influencia en la configuración de la Junta de Gobierno. No se puede olvidar que el problema más candente cuando se efectuó el traspaso de poderes había sido la organización del futuro ejército. Se había llegado a un acuerdo previo con EE.UU. para que el ejército fuera fruto de la unidad de los ex-guardias nacionales, que no tuvieran delitos de sangre, con los combatientes sandinistas. Por ello se nombró, en un principio, como ministro de Defensa, al ex-guardia Bernardino Larios, que había desertado de la Guardia Nacional y era aceptado por toda la oposición; y, como segundo suyo, se había pensado en Edén Pastora, para que estuviera garantizada la integración entre la Guardia y los sandinistas ${ }^{35}$. Sin embargo, cuando a los pocos días cambiaron las circunstancias con la huida de la Guardia Nacional, el FSLN quedó ya libre de compromisos previos. Primero se contempló la opción de que la jefatura del ejército la asumiera Henry Ruíz, aunque recayó finalmente en Humberto Ortega, que fue el elegido por la comisión encargada del traspaso de poderes con William Bowdler a la cabeza, y nombrado oficialmente en diciembre de 1979. De ese modo, no solo el FSLN se imponía en todos los órganos del Estado, sino que se aseguraba la hegemonía de la tendencia «Tercerista»: a partir de entonces, serían los representantes de dicha tendencia los que estarían integrados en posiciones privilegiadas de la Dirección Nacional, de la cúpula del ejército y de la Junta de Gobierno.

Con esa correlación de fuerzas, pronto surgieron desavenencias en el funcionamiento de la Junta de Gobierno. Como los miembros del FSLN -Sergio Ramírez, Daniel Ortega y Moisés Hassan- eran mayoría, aunque presentaran individualmente sus iniciativas, siempre conseguían que fueran aprobadas y nunca podían perder las votaciones. Además, en la práctica, se daba continuamente una duplicidad del poder ejecutivo, con fricciones y cruces permanentes de competencias entre la JGRN y la Dirección Nacional del FSLN hasta el punto de que el poder colegiado de los nueve comandantes se superponía con frecuencia al de la Junta.

A ese escollo, se agregaron otros dos problemas: de una parte, la frágil unidad entre los miembros de Dirección Nacional y los cuadros de la Asam-

35 Echeverría, 2006: 134. 
blea Sandinista, ya que el criterio de la primera era indiscutido; de otra, las discrepancias incrementadas por la participación de internacionalistas durante los primeros meses -ideológicas y, en consecuencia, sobre el modelo económico que deseaban implantar- en los diferentes órganos de poder. Todo ello desembocó en una perjudicial pasividad tanto de los miembros del FSLN como de los afectos al sandinismo en general respecto a concretar una identidad objetiva y realista de lo que deseaban que fuera la Revolución. Fue una ausencia de definición clara que incrementó las susceptibilidades.

Violeta Barrios de Chamorro y Alfonso Robelo abandonan la Junta de Gobierno

$\mathrm{Si}$ algunas consecuencias de la «Asamblea de las 72 Horas» se habían hecho ya visibles y en los sectores ajenos al FSLN se había sembrado la desconfianza, ésta se vio incrementada cuando el 16 de abril de 1980 la JGRN autorizó por decreto la ampliación del Consejo de Estado -el órgano legislativo- incluyendo a 14 representantes de las organizaciones de masas del FSLN $^{36}$. Esa modificación colocaba también al Frente en un lugar preeminente en el poder legislativo. Por esa causa, Violeta B. de Chamorro dimitió el 19 de abril. La explicación oficial fue la renuncia por problemas de salud, pero sus verdaderas razones fueron el desacuerdo con la orientación que se estaba imponiendo y el incumplimiento de las promesas de democracia. Cuando Alfonso Robelo hizo lo mismo el 22 del mismo mes, fue cuando la Junta quedó bajo el pleno control del FSLN y con tres miembros únicamente: Daniel Ortega, Sergio Ramírez y Moisés Hassán. Solo ellos firmarían los despachos que se emitieron hasta el 10 de Mayo de 1980.

Las dimisiones de Alfonso Robelo y Violeta B. de Chamorro fueron una consecuencia del punto de vista que consideraba la alianza con el resto de los partidos -conservadores, liberales, de centroizquierda y extrema izquierdaalgo coyuntural y solo justificado para evitar un rechazo directo de EE.UU. En base a ese análisis, el FSLN no encontraba ya razones para perpetuar esas alianzas y entre los miembros de los órganos de Gobierno comenzaron los recelos y las críticas mutuas: unos, hacia el Frente, al que acusaron de que pretendía imponer un modelo socialista, y el Frente, hacia los otros partidos

${ }^{36}$ La modificación se produjo por el Decreto n ${ }^{\circ} 406$ de la Junta de Gobierno (JGRN), de 19 de mayo de 1980, Índice de Leyes y Decretos (1979-2009), Corte Suprema de Justicia y Biblioteca Jurídica de la República de Nicaragua. 
contrarios a la revolución, que buscaban apoyos, en su opinión, entre los elementos más reaccionarios para imponer otros modelos de Estado.

Tras las renuncias de Violeta B. de Chamorro y Alfonso Robelo, el 19 de mayo de 1980 se reformó el Estatuto Fundamental de la República, quedando así su artículo 11: «La Junta de Gobierno estará integrada por las cinco personas que decrete el presente Estatuto Fundamental, designadas por el movimiento revolucionario de entre los distintos sectores políticos y socio económicos nicaragüenses ${ }^{37}$. En base a ese artículo pudieron ser sustituidos Violeta B. de Chamorro y Alfonso Robelo por Arturo J. Cruz y Rafael Córdova Rivas y la Junta quedo constituida otra vez por cinco miembros, sumando los dos anteriores a los que habían permanecido: Sergio Ramírez, Moisés Hassán y Daniel Ortega.

Violeta B. de Chamorro y Alfonso Robelo estaban en lo cierto cuando vislumbraron las intenciones del FSLN y plantearon su renuncia: el FSLN se encaminaba a monopolizar las instituciones del Estado. Con el convencimiento de que la revolución no hubiera sido posible sin su papel dirigente, el Frente quiso garantizar su permanencia provocando las exclusiones necesarias para sus fines. Así, su hegemonía quedaba asegurada desde los inicios de la nueva andadura y el resto de los grupos que antes le habían prestado su apoyo se lo irían retirando en poco más de un año. A este respecto, quien fuera Procurador General durante los primeros años de este período, Ernesto Castillo, publicó lo siguiente:

No hay duda de que se pudo tener un poco más de cuidado por parte de la dirigencia del FSLN en las relaciones con Violeta y Alfonso Robelo. (...) Ellos aceptaron muchas cosas. Si examinamos el contenido y trascendencia de las medidas jurídicas y políticas que se tomaron con las firmas de Violeta y Alfonso, habrá que reconocer que fueron más allá de sus características ideológicas y sociales individuales. Pero no supimos valorarlo en su momento ${ }^{38}$.

Obviamente, no se tuvo ese cuidado y ambos miembros terminaron dimitiendo de sus puestos. Del mismo modo, el Departamento de Estado Norteamericano se inquietó muy pronto con los comportamientos de los miembros del FSLN en la Junta, por provocar el estrechamiento de los márgenes del resto de los partidos que habían constituido la oposición a Somoza. Una de las consecuencias fue el empeoramiento irreversible de las relaciones con EE.UU.

37 Decreto $\mathrm{n}^{\mathrm{o}} 406$ de la Junta de Gobierno (JGRN), de 19 de mayo de 1980, Índice de Leyes y Decretos (1979-2009), Corte Suprema de Justicia y Biblioteca Jurídica de la República de Nicaragua.

38 El Nuevo Diario, Managua, 17-3-2006. 
Meses más tarde, dimitirían también Arturo Cruz y Moisés Hassan. Este último, abandonó la Junta en 1981, poco antes de que Daniel Ortega fuera investido, el 4 de marzo de ese mismo año, como Coordinador de la tercera Junta de Gobierno ${ }^{39}$.

\section{El inicio del ascenso de Daniel Ortega}

Daniel Ortega pudo escalar esa posición de Coordinador -una vez máspor la valoración de su hermano Humberto como Jefe del ejército. Y fue ese nombramiento el que le permitiría más adelante ser el candidato a presidente por el FSLN cuando se convocaran las elecciones en 1984.

El cargo de «Coordinador» era el equivalente al de primer ministro de la Junta de Gobierno, reducida ya a un triunvirato, dado que, una vez formalizadas las salidas de Moisés Hassan y Arturo Cruz, quedaron únicamente Daniel Ortega, Sergio Ramírez y Rafael Córdova, sin que ya se intentara alcanzar nuevamente el número de cinco $^{40}$. Con ese reforzamiento de la figura de Daniel Ortega, el FSLN controlaba gran parte del aparato del Estado y el conjunto de las fuerzas de Seguridad y Defensa. El Frente empezó a funcionar como un partido político de vocación estatal y la Junta gobernaba por decreto y ejecutando las decisiones que emanaban de la Dirección Nacional.

Este encumbramiento de la figura de Daniel Ortega terminó de convencer al nuevo presidente de EE.UU., Ronald Reagan, de que Nicaragua perseguía convertirse en otra Cuba, como una plataforma para la penetración del comunismo soviético y como «exportadora» de revoluciones a toda Centroamérica ${ }^{41}$. A ello se añadió que la convocatoria de elecciones se retrasara, puesto que se había empezado prometiendo que se haría a los tres años y finalmente se había postergado hasta los cinco, lo que alimentó las desconfianzas de la administración Reagan.

La Junta de Gobierno estaba ahora compuesta solo por sandinistas, pero el FSLN no lo consideraba grave, dado que se había concebido como algo temporal desde un principio y solo hasta que se convocaran elecciones. Sin embargo, es cierto que el FSLN se consideraba con derechos especiales por

${ }^{39}$ Moisés Hassan sería después alcalde de Managua de 1981 a 1985 y en 1988 fundó el partido de izquierda Movimiento de Unidad Revolucionaria (MUR).

${ }^{40}$ Rafael Córdova había sido un fuerte opositor al somocismo y militante del partido Conservador. Fue integrante de la JGRN de 1980 -tras la salida de Violeta Chamorro y Alfonso Robelo- a 1984 y diputado de 1985 a 1990 por el P.C.

41 Álvarez Montalván, 1996: 37 y ss. 
haber escalado un durísimo camino hasta derrotar a la dictadura somocista. Había perdido a tantos de los suyos en el camino que se sentía legitimado para gobernar, además de que se percibía a sí mismo como el partido protector y defensor de la revolución, que nunca pudo desechar los temores de una posible involución hacia una muy desvalorizada democracia formal.

De otra parte, pesaba la convicción doctrinaria de que en el futuro se precisaba un partido de vanguardia para hacer efectivo el cambio $\mathrm{y}$, en el ideario sandinista, era prioritario poner fin a las desigualdades y asentar unas instituciones que crearan un verdadero nuevo orden social más justo. Por todo ello, el sandinismo decidió centrarse en la reconstrucción del país y en la implantación de un sistema productivo y económico que pensaban que atendería mejor a las necesidades de las clases más castigadas en el pasado, y dejó el proceso electoral en un segundo plano, para más adelante.

Con el incremento de competencias de la JGRN -siempre mediatizada por la Dirección Nacional- quedaba meridianamente claro que se estaba logrando lo que se había perseguido subrepticiamente: el reforzamiento desequilibrado del poder ejecutivo, que ya incluía en la práctica las facultades legislativas y elegía también a los miembros del poder judicial. Esa concentración de poder sentaría los cimientos sobre los que se edificara más tarde el gobierno presidencialista de Daniel Ortega, tras las elecciones de 1984. Cuando aquél alcanzó la presidencia, sustituyó a la JGRN, que desapareció de los órganos del Estado.

\section{El «poder legislativo»: el Consejo de Estado y sus modificaciones}

El Consejo de Estado fue concebido como una cámara legislativa que compartiría sus competencias con la JGRN, aunque con el tiempo pasó a ser únicamente una cámara deliberativa. Su objetivo inmediato era organizar las elecciones en el ya mencionado plazo de tres años, según el esquema inicial. Pero desde su creación pasó por varias modificaciones.

El primer Consejo de Estado, de composición plural, sería el embrión de la actual Asamblea Nacional, el Parlamento. Como no había habido elecciones, y sus componentes estaban allí por designación, se intentó en un principio que estuvieran representados todos los sectores del país: políticos, empresariales, gremiales, sindicales, asociaciones civiles, de mujeres y hasta de militares. Este último sector era lo que, en aquél entonces, se conocía como Fuerzas Armadas y tenía una dirección política, a la usanza de los ejércitos del campo socialista, que se ocupaba del trabajo de formación política de los militares fueran oficiales, clases, soldados, o trabajadores civiles. Dichas Fuerzas Arma- 
das estuvieron representadas en el Consejo por el comandante Hugo Torres ${ }^{42}$. Las Fuerzas Armadas empezaron abarcando el Ministerio de Defensa y el de Interior juntos, en lo que denominaron «jefatura de coordinación», pero fue poco útil y se fueron independizando ambos Ministerios.

La pluralidad del Consejo de Estado no tuvo larga vida. Al igual que la Junta de Gobierno, en cuanto se tuvo la certeza de que el aparato militar y político de los Somoza se había desmoronado, se inició su recomposición para que también en él estuviera garantizara la hegemonía del FSLN. Lo único que entonces pensaban que podría entorpecer el proyecto de implantar un régimen socialista en el futuro -que entonces, con demasiado optimismo, se veía no muy lejano- era que se fraccionara la frágil unidad interna del FSLN. Por eso el resto de las medidas fueron:

1. Control total de las fuerzas armadas, que se logró en cuanto Humberto Ortega logró ser aceptado como Jefe del Ejército.

2. Limpieza rígida de los restos del somocismo.

3. Medidas de orden económico que sacudieran a los sectores del capital que pudieran frenar el acelerado proceso hacia un régimen realmente de izquierdas. Ya no sería «cogobernante», sino únicamente tolerante con los sectores económicos de la burguesía, siempre que respetaran el proceso.

4. La estructuración de un aparato de gobierno paralelo a través de las comisiones constituidas dentro de la Asamblea Sandinista, como la Comisión de Estado, la Comisión Política y la Comisión de Defensa y Seguridad ${ }^{43}$.

En cambio, al contrario que la JGRN, cuya evolución fue la adquisición de más competencias -aunque siempre bajo la Dirección Nacional-, las modificaciones que sufrió el Consejo de Estado le fueron vaciando de contenido y se realizaron también mediante decretos: el primero fue el de 16 de Abril

${ }^{42}$ Hugo Torres recibió el título honorífico de Comandante Guerrillero -que se otorgaba a los líderes más destacados de la lucha insurreccional- por decreto de la JGRN. Posteriormente estuvo en la primera Dirección General de Seguridad (DGSE) durante unos meses de 1979; fue viceministro de Interior en los primeros meses de $1980 \mathrm{y}$, por último, fue representante de la Fuerzas Armadas ante el Consejo de Estado (Jefe de la Dirección Política del Ejército Popular Sandinista, EPS) durante el resto de la década de 1980.

${ }^{43}$ La Comisión de Estado fue una comisión organizada para velar por la gestión y la vida del partido, dentro del Estado. La Comisión de Política Exterior y el Consejo de Defensa y Seguridad fueron comisiones organizadas dentro de la Asamblea Sandinista, como apoyo a la Dirección Nacional, para el análisis de los asuntos internacionales y de defensa. Ambas comisiones dejaron de funcionar en 1982. Entrevista de la autora con Ernesto Castillo, Managua, noviembre, 2012. 
de 1980 -en el que se sacrificaba la pluralidad inicial del Consejo de Estado para encumbrar más al FSLN- y que sería el último firmado por Alfonso Robelo y Violeta B. de Chamorro ${ }^{44}$. El segundo, el de 2 de Mayo de 1980, por el que se emitió un Estatuto para redefinir las facultades del Consejo cuyo resultado fue la reducción práctica de las competencias legislativas que lo convertían en un mero órgano asesor. Era la Junta la que conservaba las facultades de legislar -si el Consejo le sometía algún proyecto a su consideración- y podía rechazarlo sin más trámite que la información del por qué del rechazo. También competían a la Junta las potestades de publicación y de interpretación auténtica y se convertía así en el órgano con mayor poder. Ese decreto fue firmado en la etapa de la trilogía constituida por Daniel Ortega, Sergio Ramírez y Moisés Hassan ${ }^{45}$.

El 19 de mayo de 1980, cuando fueron incluidos en la Junta Arturo J. Cruz y Rafael Córdova Rivas, se reorganizó el Consejo ampliándolo hasta 47 miembros por la entrada de otras organizaciones afines al sandinismo, que no se habían contemplado antes, y que llegaron a representar el $60 \%$ del total ${ }^{46}$. Era una reforma de gran calado si se tiene en cuenta que, en su funcionamiento inicial, cuando el Consejo de Estado estaba compuesto por representantes de todas las organizaciones, la JGRN había establecido que fueran 33 sus miembros, de los que 17 ya eran de clara afiliación sandinista. Ahora, el incremento hasta 47 garantizaba que funcionaría más como órgano de consulta del FSLN que como un espacio parlamentario tradicional. En realidad, era ya la Junta de Gobierno la que ejercía las facultades legislativas.

Meses después, cuando Daniel Ortega anunció el 12 de noviembre de 1980 que no convocaría elecciones hasta 1984, se retiraron del Consejo de Estado una decena de agrupaciones representativas de la burguesía nacional, entre ellas el Movimiento Democrático Nicaragüense (MDN), por considerar que el Gobierno se había apartado de lo dispuesto en el Estatuto Fundamental.

Con todos estos cambios, había dado comienzo una sangría monetaria hacia el exterior en forma creciente y a descapitalizarse las empresas en Nicaragua. El FSLN se asentaba fuertemente como medida para prevenir y sancionar esas actividades y el sector privado se dio cuenta de que los miembros no sandinistas de la Junta no tenían la posibilidad de ejercer ninguna influencia.

${ }^{44}$ Decreto $n^{\circ} 374$, de 16 de Abril de 1980, Índice de Leyes y Decretos (1979-2009), Corte Suprema de Justicia y Biblioteca Jurídica de la República de Nicaragua.

${ }^{45}$ Decreto $\mathrm{n}^{\circ} 388$ de la JGRN, de 2 de mayo de 1980, Índice de Leyes y Decretos (19792009), Corte Suprema de Justicia y Biblioteca Jurídica de la República de Nicaragua.

46 Decreto $\mathrm{n}^{\circ} 406$ de la JGRN, de19 de mayo de 1980, modificando el artículo 11 del Consejo de Estado, Índice de Leyes y Decretos (1979-2009), Corte Suprema de Justicia y Biblioteca Jurídica de la República de Nicaragua. 
Fue entonces cuando aumentaron los temores de toda la oposición, comenzó la amenaza más seria del Gobierno de Estados Unidos y de gobiernos vecinos por salvaguardar sus intereses. Como respuesta, el Gobierno del FSLN orientó todos sus esfuerzos hacia la defensa de la revolución, lo que le llevó a intensificar sus relaciones especialmente con los países socialistas y a priorizar a la población urbana en detrimento de la rural, que sufriría las consecuencias ${ }^{47}$.

En ese clima de crispación, el FSLN acusó a los partidos salientes del Consejo de Estado de sabotear las instituciones revolucionarias y el programa de unidad nacional, pero ya había conseguido tener garantizada su preeminencia tanto en la Junta de Gobierno como en el Consejo de Estado.

\section{El Poder Judicial}

Los órganos jurisdiccionales, como el resto de las instituciones, tuvieron que reorganizarse por completo después del triunfo de la revolución. El sistema judicial de la época de los Somoza, aunque teóricamente era tan democrático como cualquier otro de América Latina, en la práctica era un coto privado de la Guardia Nacional, ejército y policía, tanto en lo referente a delitos comunes, como políticos. El sometimiento a los intereses de la familia gobernante, igual que a los sectores más adinerados del país, y próximos a los Somoza, era total y la Justicia no fue más que un esperpento al servicio de la dictadura.

No obstante, la nueva Junta de Gobierno decidió no modificar el sistema de nombramientos ni la jerarquía piramidal de la legislación existente, según la cual, el gobierno nombraba a la Corte Suprema, ésta a su vez a los magistrados de apelaciones, y éstos a los jueces de distrito, locales y civiles o penales, o a los que actuaban en las dos ramas. Pero sí se dieron cambios considerables en lo referente al contenido y a las personas responsables de las diferentes instancias

Tradicionalmente, en Nicaragua no había existido una verdadera carrera judicial -con exámenes o pruebas a superar que favorecieran la profesionalidad de los jueces- ni tampoco algún sistema alternativo por el que los órganos superiores fueran elegidos por los órganos inferiores. Sin embargo, aún cuando se mantuvo que el gobierno designara desde la cúspide de la pirámide $\mathrm{y}$, aparentemente, el poder ejecutivo controlara totalmente al judicial, no era del

47 El FSLN se había nutrido muy fundamentalmente de los sectores jóvenes de las ciudades, estudiantiles sobre todo. A pesar de emprender una reforma agraria y tener la intención de mejorar el nivel de vida del campo, a la hora de las restricciones se ocupó más del abastecimiento de la ciudad que compondría sus levas en la «Guerra de la Contra». 
todo cierto por la existencia del juicio con jurado popular, de larga tradición en toda América. El jurado popular podía fallar de modo diferente al órgano superior del tribunal y ése fue el motivo de que el FSLN implantara la «Justicia Especial» que dio lugar a los «Tribunales Especiales» en diciembre de 1979, donde el poder ejecutivo pudiera tener un control verdaderamente efectivo del aparato judicial.

Dicha «Justicia Especial», propia de momentos críticos y etapas de transición política es conocida actualmente con el término de «Justicia Transicional» ${ }^{48}$. Su práctica se considera inaugurada en el Proceso de Nuremberg, tras la Segunda Guerra Mundial En esa ocasión, el Acuerdo concluido en Londres el 8 de agosto de 1945 entre los Gobiernos de los Estados Unidos de América, Francia, Reino Unido de Gran Bretaña y la URSS, vencedores en la Segunda Guerra Mundial, instauró la novedad de que los individuos tenían deberes y obligaciones internacionales que estaban por encima de su deber de obediencia al Estado ${ }^{49}$. El proceso tuvo el mérito de constituir la primera Corte supranacional, pero, junto a ello, utilizó ilegalmente la retroactividad y se incumplieron un sinnúmero de principios de seguridad jurídica. Se criticó duramente por muchos el carácter que le atribuyeron de linchamiento legal de los vencedores frente a los vencidos. Sin embargo, fue considerado positivo por un buen sector de juristas por tratarse de crímenes contra la Humanidad ${ }^{50}$.

En Nicaragua se utilizó la jurisdicción especial, como en muchos otros lugares, después del precedente de Nuremberg. Según Anika Oettler, hubo tres razones para aplicar la justicia transicional: evitar las venganzas personales, juzgar y no dejar inmunes las violaciones a los derechos humanos y demostrar la capacidad y voluntad del sandinismo de aplicar las normas internacionales de derechos humanos ${ }^{51}$.

El nuevo gobierno, no creyó conveniente mantener el cuerpo jurídico anterior, pero decidió no derogarlo porque, siendo una legislación formalmente democrática, aunque los Somoza la incumplieran sistemáticamente, se necesitaba esa imagen ante la comunidad internacional. Sin embargo, también

48 Con ese término se designaron desde 1990 las formas especiales de impartir justicia en épocas de transiciones, especialmente después de dictaduras, aunque más tarde se ha extendido a significados más amplios, como Comisiones de la Verdad o casos de corrupción, incluso, en períodos de violencia colectiva. Véase para mayor ampliación: Oettler, 2013: 7-27.

${ }^{49}$ Ortíz Treviño, www.juridicas.unam.mx

50 Véase a este respecto: Carrillo Salcedo, 1999.

51 De hecho, ya se habían producido muertes por iniciativas individuales. Dos de los casos fueron los del famoso torturador somocista llamado «Macho Negro» y la matanza de la cárcel de La Pólvora, en Granada. Ambas denunciadas por la Comisión Interamericana de Derechos Humanos, en 1981. Oettler, 2013: 16. 
debía procesar a los ex-guardias nacionales y fue entonces cuando se optó por elaborar una legislación paralela $\mathrm{y}$, tras los primeros ataques de la «Contra», decretar un «Estado de Sitio» para poder promulgar nuevas leyes. Así surgieron la Ley de Mantenimiento y Seguridad Pública, la Ley Especial de Emergencia y las de los Tribunales Especiales y Populares.

Todo estaba orientado a crear un aparato de poder autónomo, dejando abandonada en la práctica una estructura jurídica, más o menos obsoleta, aunque no derogada, que pervivió junto a otra paralela, con leyes muy especiales, para las cuestiones del Estado y el mantenimiento del orden, que el FSLN ya percibía como «un nuevo orden». De hecho, la estructura jurídica de la revolución, definida en el Estatuto Fundamental y en el de Derechos y Garantías, especificaba qué partes del cuerpo jurídico permanecerían vigentes. Así, bajo los nuevos principios, se sustituyó la concepción somocista de propiedad privada, de libertad de contratación y de participación de las minorías en la política, por los conceptos acuñados por la revolución de «función social de la propiedad»-tanto individual como colectiva- «sujeción de los intereses individuales a los colectivos y garantía de la participación popular en la gestión del Gobierno ${ }^{52}$. Dichos principios fueron ampliamente debatidos y explicados, como básicos para el nuevo modelo de Estado que se perseguía, en la Asamblea Sandinista de $1982^{53}$. De hecho, fueron los que inspiraron las leyes que concretaban los postulados del Estatuto Fundamental y del de Derechos y Garantías. El área judicial reflejaba de ese modo la existencia de unas estructuras de partido, a las que se supeditaban claramente las del gobierno. En palabras de Ernesto Castillo:

En el caso mío, como miembro de la Asamblea y de la Comisión de Estado -que eran órganos de la estructura del FSLN- se me asignó encabezar el «Comité Jurídico», que formaba parte de la Comisión de Estado. Eso significaba colocar bajo mi responsabilidad los asuntos jurídicos nacionales, toda el área jurídica. Y eso era por ser yo un cuadro del Partido, no era por ser Procurador General de Justicia de la República; al contrario, fui Procurador por ser un cuadro veterano del FSLN ${ }^{54}$.

Siguiendo los mencionados parámetros, la Junta de Gobierno nombró a la Corte Suprema de Justicia el 20 de julio de 1979, mediante decreto y en ella, como en otras áreas, se ponía a la cabeza a un cuadro del FSLN para

${ }^{52}$ Las garantías se establecieron en los artículos 1, 27 y 48 del Estatuto.

${ }^{53}$ II Asamblea Sandinista Héroes y Mártires en la defensa de la revolución, finalizada el 31 de enero de 1982, "Año de la unidad frente a la agresión”, AECM, exp. 058, 059 y 060.

54 Entrevista con Ernesto Castillo, Managua, mayo de 2013. 
que todos los funcionarios públicos dependieran de él. O sea, que por ser del Partido, se tenía competencias en el Gobierno.

\section{Las desavenencias del Poder Judicial con la Dirección Nacional}

La Corte Suprema de Justicia fue la primera institución que había que dotar de nuevos integrantes y la Junta de Gobierno, con el criterio de elegir a renombrados abogados que tuvieran en común el haber sido antisomocistas, eligió como primer presidente a Roberto Argüello Hurtado y como primera vicepresidenta a Vilma Núñez Escorcia. Ambos procedían de las filas conservadoras, aunque tiempo antes del triunfo de la revolución, Vilma Núñez era ya del FSLN y Roberto Argüello era colaborador del mismo. Ser nombrado para la Corte Suprema era un alto honor y ellos debían elegir al resto, lo que hicieron con el único criterio de que fueran personas honestas y profesionales de reconocido prestigio, tratando de compensar las carencias de la estructura jurídica existente. Según la citada vicepresidenta, Vilma Núñez, fueron nombrados en los primeros días del triunfo revolucionario y, en su caso, le llegó la noticia estando todavía encarcelada ${ }^{55}$.

En la elección del resto de miembros, se incluyeron magistrados también conservadores, aunque simpatizantes del FSLN, y se aseguró una Corte que fuera ejemplo de pluralismo ideológico. Puesto que la oposición parlamentaria legalizada se había limitado siempre al Partido Conservador y, más tarde, también al Partido Liberal Independiente (PLI), se eligieron magistrados de entre ambos partidos, además de los del FSLN. Se quiso que estuvieran representadas las diferentes ideologías participantes en la lucha contra el somocismo y el resultado fue: tres del FSLN, tres de otros partidos y uno independiente ${ }^{56}$.

La Corte Suprema fue en uno de los lugares donde se manifestaron con mayor virulencia las consecuencias de la concentración del poder en la Dirección Nacional, sobre todo cuando se iba recrudeciendo la «Guerra de la Contra». Se iba perfilando un gobierno que no daba importancia a las formalidades jurídicas, entre otras cosas, porque pensaba que la revolución permanecería

${ }^{55}$ Cuando se dio el triunfo, Vilma Núñez estaba presa y el gobierno en el exilio difundió por Radio Sandino quienes eran las personas que se iban a hacer cargo de diferentes puestos. En esas listas apareció su nombre como miembro de la Corte Suprema de Justicia y llegó un guardia y le dijo que la iban a matar porque en la radio de Costa Rica estaban diciendo que iba de ministra. Así supo Vilma Núñez que la nombrarían para la Corte Suprema. Entrevista de la autora con Vilma Núñez, Managua, 2010.

${ }^{56}$ Envío Digital, 88 (Managua, octubre de 1988). 
para siempre. Y, a decir de la vicepresidenta Vilma Núñez, tanto el presidente Argüello como ella, tuvieron que aceptar cambios legales que consideraban erróneos, siempre bajo el argumento de las necesidades de «defensa» de la revolución. Hasta que llegó un momento en que los siete magistrados de la Corte Suprema decidieron que se atendrían a la ley y no se doblegarían ante requerimientos de otra índole. La Dirección Nacional les calificó de legalistas y reaccionarios, nunca creyó en sus calidades revolucionarias y les hizo sentirse permanentemente como sospechosos. De hecho, lo que la cúpula del FSLN pensaba de ellos era que, por su procedencia conservadora, aunque fueran simpatizantes del Frente, les costaba disciplinarse a las estructuras del partido.

La justificación de la Dirección Nacional era que la vieja legislación se había mantenido por facilitar la convivencia del FSLN tanto con las estructuras democráticas del exterior como con las internas; por las relaciones internacionales y por la burguesía del interior. Pero el mantenimiento de los códigos de la época anterior iba unido a la pretensión reiterada de que los magistrados no los tuvieran en cuenta y eso, desde el punto de vista de los juristas, era algo inaceptable. La realidad era que las instancias judiciales habían quedado sujetas a la disciplina del partido y ello originaba problemas continuamente. Los Magistrados insistían en que, si el ordenamiento jurídico se había dejado intacto, había que respetarlo y, de acuerdo con el principio de supremacía de la Constitución, aquello que no contradijera al Estatuto Fundamental -que era la nueva Constitución-, se tenía que aplicar. Sobre esa falta de rigor y las discrepancias continuas con la Dirección Nacional, dice la Vicepresidenta:

Fue entonces cuando surgió aquello de «la revolución es fuente de derecho». Si uno analiza a fondo esa frase, y se piensa en las fuentes del derecho, en el origen del derecho, se da cuenta de que es una realidad que el poder político es el que genera las leyes, pero ellos no lo interpretaban de esa manera. Con esa frase, que fue de Bayardo Arce, pretendían argumentar que todo lo anterior quedaba borrado, pero sin promulgar leyes nuevas ni darnos instrumentos para poder actuar; quisieron justificar que todo lo que hiciera la revolución valía. Y esa frase tenía un contenido válido si se hubiera interpretado de la manera correcta, pero quedó totalmente desvirtuada y como una muestra de arbitrariedad y autoritarismo. Eso trajo muchos problemas, que se iban superando porque había respeto. No nos faltaban al respeto, pero querían imponérsenos ${ }^{57}$.

Los enfrentamientos más serios que la Corte Suprema de Justicia tuvo con la Dirección Nacional -especialmente con el ministro de Interior Tomás Borge- se debieron a la creación de los Tribunales Especiales y la promulgación de algunas de leyes.

${ }^{57}$ Entrevista de la autora con Vilma Núñez, Managua, enero de 2012. 


\section{Los Tribunales Especiales}

Los Tribunales Especiales fue el nombre que se dio, de modo coloquial, a todos los nuevos tribunales porque respondían a una jurisdicción especial y no a la ordinaria. Pero, en sentido estricto, se dividieron en dos clases: Tribunales Especiales y Tribunales Populares.

Los Tribunales Especiales estuvieron vigentes de 1979 a $1981^{58}$. Su objetivo fue juzgar a todos los antiguos miembros de la Guardia Nacional -que en número de 7 u 8.000 abarrotaban las cárceles- y a todos los miembros del aparato estatal o gubernamental del antiguo régimen, de la dictadura, en juicios casi sumarísimos, que se desarrollaban con la máxima rapidez. Cada tribunal constaba de tres miembros, que tenían que ser mayores de 21 años y de reconocida solvencia moral. Asimismo, uno de sus miembros debía ser abogado o estudiante de Derecho, al menos en su penúltimo curso.

$\mathrm{Su}$ justificación fue siempre el permanente "estado de emergencia», por el que se suspendían las garantías constitucionales y los recursos de Habeas Corpus. Fue evidente que había un temor muy grande a perder cualquier conquista de la revolución y un recuerdo vivo de que la violencia había sido la respuesta habitual de los gobiernos a las demandas de un cambio social. Finalmente, sin embargo, se terminó legislando que el recurso de Habeas Corpus jamás se podría suspender, aunque estuvieran suspendidas las garantías constitucionales.

Los Tribunales Populares, tenían las mismas características y se crearon más tarde para juzgar a los «contras» ${ }^{59}$. A ellos se vieron sometidos gran cantidad de campesinos, a los que se incluía entre los enemigos de la revolución solo porque la «Contra» hubiera pasado por la zona en donde ellos vivían y trabajaban y les hubieran dado de comer, pese a que era del dominio público que, de no hacerlo, los podían matar. El campesinado continuó siendo el sector más golpeado, como ya lo había sido en la época de los Somoza, porque si pasaba la «Contra» por su territorio, sufrían un tipo de peligro, pero si se les tomaba como «contras» a ellos, el peligro llegaba de los contrarios.

Los nuevos tribunales fueron tan rápidos que, si un juicio ordinario se podía prolongar una media de dos o tres años, por la ley de creación de los

58 Se crearon por el Decreto 185, aprobado el 29 de noviembre de 1979 y publicado en $L a$ Gaceta $\mathrm{n}^{\circ} 75$. Permanecieron hasta febrero de 1981. El sistema constaba de nueve tribunales especiales y de tres tribunales de apelación. Fue designado un fiscal especial junto con un equipo de nueve ayudantes.

${ }_{59}$ Se crearon por el Decreto $\mathrm{n}^{\circ} 1.233$, aprobado el 11 de abril de 1983 y publicado en $L a$ Gaceta, $\mathrm{n}^{\mathrm{o}}$ 82, Managua, 12-4-1983. 
Tribunales Especiales -suprimido en su concepción el jurado popular- los jueces, militantes sandinistas, fallaban en el término de ocho días ${ }^{60}$. O sea, que en ocho días se podía condenar a un acusado a treinta años de prisión. Asimismo, hubo ocasiones en que se dieron infracciones tan flagrantes como la competencia de los fiscales para nombrar a los abogados defensores de los acusados.

Asimismo se repitió, una vez más, el frecuente caos que se produce en situaciones de confrontaciones bélicas o posbélicas: que una parte de los detenidos fueran civiles denunciados y encarcelados en los barrios porque, en medio de la confusión inicial, habían sido objeto de revanchas personales y otras muchas razones no políticas. Quien fuera viceministro de Interior, Luis Carrión, añadía a lo anterior que las cárceles se llenaron en los primeros días posteriores al triunfo de la revolución y recordaba una triste anécdota en relación con esas detenciones que puede ser un buen ejemplo:

Hace poco me encontré yo con un señor que me comentó que había estado preso en aquella época. Yo le pregunté por qué. Y me dijo que, como él era técnico de comunicaciones, lo contrataba la Guardia para reparar equipos y, con eso, ya se le consideró pro-Guardia ${ }^{61}$.

También criticaron el procedimiento la Comisión Interamericana de Derechos Humanos de la OEA de 1981 y el Informe de Amnistía Internacional, igualmente de 1981. La Comisión reconoció las circunstancias excepcionales por las que pasaba el país y las profundas consecuencias que había tenido sobre el conjunto de la sociedad el proceso vivido y valoró los esfuerzos que estaba realizando el entonces Gobierno de Reconstrucción Nacional, pero denunció tanto la escasez de abogados profesionales, como por la brevedad de los juicios, la falta de motivación de las sentencias, negación de garantías procesales, entre otros ${ }^{62}$.

El Informe de Amnistía Internacional denunció arbitrariedades, sentencias basadas en la filiación política o en la posición en la cadena de mando ${ }^{63}$.

Contrariamente, en defensa de dichos juicios se expusieron tres razones:

${ }^{60}$ Ley de la creación de Tribunales Especiales. Decreto $\mathrm{n}^{\circ}$ 185, aprobado el 29 de Noviembre de 1979 y publicado en La Gaceta n ${ }^{\circ}$ 75, Managua, 5 -12-1979.

${ }^{61}$ Entrevista de la autora con Luis Carrión. Managua, noviembre 2012. Luis Carrión fue uno de los nueve comandantes de la Dirección Nacional y viceministro de Interior, segundo del Ministerio presidido por Tomás Borge.

${ }^{62}$ Comisión Interamericana de Derechos Humanos de la OEA, sección D del Capítulo IV sobre el Derecho a la Justicia y al Proceso Regular de su Informe de 1981: 89. http://www. cidh.oas.org/annualrep/88.89span/capitulo5.htm (fecha de verificación: 28/10/2015).

63 Amnistía Internacional, 1981: 16-35. 
1) Que se había decidido que no se sentenciaría a muerte ni a los guardias con delitos de sangre, ni a contrarrevolucionarios civiles con el deseo de que la justicia de la revolución superara moralmente a la cubana. Por lo tanto, había que juzgar y dictar condenas de cárcel ${ }^{64}$.

2) Que los tribunales ordinarios estaban sobrecargados y no era posible tener las cárceles rebosando de presos a la espera de juicio.

3) Con posterioridad, se añadió a la justificación que casi ningún ex-guardia somocista había reclamado un juicio diferente del que se les hizo en los Tribunales Especiales. Según ese argumento, les convenía mucho más que si hubieran sido juzgados por jurados populares constituidos, muy probablemente, por quienes habían sido sus víctimas.

Por otra parte, desde un punto de vista político, se consideraron estos juicios como parte de un «derecho para una etapa de transición» y se defendieron como sigue:

Se establecieron tribunales especiales para sancionar las actividades consideradas dañinas para el proceso de cambio, con el fin de poder actuar sin necesidad de sujetarse a formalismos establecidos en la legislación común. La sana crítica se convirtió en el más eficaz medio de prueba, sustituyendo la rigidez de la prueba tasada imperante hasta entonces.

En las ramas civil y comercial se optó, sin cambiar los códigos sustantivos, por legislar a través de decretos ejecutivos que se aplicaban por autoridades administrativas y no por las judiciales tradicionales ${ }^{65}$.

La vicepresidenta de la Corte Suprema, Vilma Núñez, calificó a ese tipo de tribunales como ilegales y parciales y realmente concebidos para deshacerse de posibles enemigos contrarrevolucionarios. Rompían el principio de «unidad de jurisdicción», que debe inspirar todo el ordenamiento jurídico, puesto que constituían un sistema paralelo de tribunales independientes del sistema de tribunales establecido, además de que los procedimientos eran sumarios.

Esa estructura de los tribunales populares y especiales fue integrada por cuadros del FSLN dirigidos por dos abogados, Mario Mejía y Nora Astorga ${ }^{66}$.

${ }^{64}$ Efectivamente, en el período sandinista hubo una postura oficial de no llevar a efecto fusilamientos. Muy al contrario, fue un tema que se debatió y se decidió no instaurar la pena de muerte ni ejecutar fusilamientos como había hecho Cuba, a pesar de la admiración que se le había profesado en tantos otros aspectos. Aunque ello no impidiera el caos de los primeros tiempos y los desmanes producto de iniciativas individuales.

${ }^{65}$ El Derecho como instrumento estabilizador en épocas de transición, AECM, (sin clasificar).

${ }^{66}$ Ambos abogados debían responder directamente ante el Procurador General de Justicia, Ernesto Castillo Martínez, como responsable del sistema jurídico en el seno del FSLN. 
Esta última, en julio de 1979 fue nombrada fiscal de los Tribunales Especiales y permaneció en ese puesto hasta octubre de 1980. Tres meses antes de su muerte -en noviembre de 1988- se le hizo una entrevista en la que ella relataba que su trabajo en la Fiscalía había sido muy duro porque se había debatido entre atender a los cargos de los ex-guardias que presentaban los expedientes y las familias suplicándole que fueran exculpados. Así lo expresaba:

Los guardias de bajo rango eran gente muy pobre, gente que eran la fuente de ingresos de su familia. Y llegaba la mujer, con su panza y con sus chavalos desnutridos, a pedirme clemencia... En esos momentos yo hubiera querido que ese guardia no tuviera crímenes para poder decir : okey, ahí esta, llevátelo... Recuerdo a una señora embarazada que durante un mes se paró todas las mañanas a la entrada de mi oficina. No me decía nada. Yo ya sabía. Diario estaba ella, con su panza y su muchachito. Y su marido estaba bien pegado, era responsable de crímenes... Yo buscaba alternativas, fui al barrio para que la ayudaran económicamente, pero... Pasé el caso a los tribunales, lo acusé y lo condenaron. Era duro, porque tenías que partirte entre lo que sentías y lo que debías hacer ${ }^{67}$.

En otras ocasiones más benévolas, a la fiscal le correspondió firmar órdenes de libertad sin tener que pasarlas por el juez, con todo lo que ello significaba también de infracciones procesales. Ella misma fue la encargada de cerrar esos tribunales en enero de 1988 y, según sus cálculos, se conocieron en ellos unos 6.000 casos, de los que quedaron libres de 1.200 a 1.400 , que no llegaron a ser juzgados. Después hubo otras amnistías por enfermedad o por razones familiares. El mayor porcentaje de los somocistas juzgados fue sentenciado a 5 años. Un $11 \%$ tuvo sentencias entre 5 y 10 años. Y a la pena máxima de 30 años se sentenció a un 12-15\%.

Las cifras de un amplio informe del Catholic Institute for International Relations (CIIR), algo superiores, señalan que durante la insurrección contra Somoza y en las semanas siguientes al triunfo revolucionario, los sandinistas capturaron a unos 7.000 u 8.000 ex-miembros de la Guardia Nacional y colaboradores civiles del somocismo. De ellos, 6.310 fueron juzgados en los Tribunales Especiales, 1.760 fueron perdonados o se dio por cerrados sus casos, 229 fueron absueltos y 4.331 fueron sentenciados a diferentes perío-

${ }^{67}$ Testimonio de Nora Astorga en entrevista a Envío Digital, en 1988. Nora Astorga había sido guerrillera del FSLN, de formación católica, muy conocida por haber propiciado la detención del guardia torturador Pérez Vega, más conocido como «el Perro Pérez», muerto después al no ser posible secuestrarlo. Cuando triunfó la revolución fue viceministra de Justicia, responsable de las finanzas del ejército sandinista y fiscal de los tribunales especiales. Finalmente, pasó dos años como embajadora de Nicaragua en la ONU y murió el 14 de febrero de 1988. 
dos de cárcel ${ }^{68}$. En 1986, el Gobierno informó que de esos 4.331, 2.157 aún permanecían en prisión ${ }^{69}$.

Nora Astorga aseguraba que, antes de juzgar a los guardias denunciados, se habían hecho investigaciones en sus barrios, preguntando por ellos a quienes les conocían, y que la gente nunca se había tomado revanchas por su cuenta. Por el contrario, cuando se había seguido la vida posterior de los encausados, habían comprobado que, en algunos casos, la decisión de dejarlos salir sin cargos había sido equivocada porque después le habían llegado pruebas de que una parte habían sido criminales y otros se habían unido a la "Contra». En cambio, la mayoría de los que habían sido condenados, al salir de la cárcel se habían unido a su familia, trabajaban y no había ocasionado más problemas ${ }^{70}$.

Otro motivo de crítica respecto a estos tribunales fue una de las prácticas que ya habían soportado los detenidos del Frente en tiempos de los Somoza, calificada por la Comisión Interamericana de Derechos Humanos como una de las mayores violaciones de los mismos: las prolongadas prisiones preventivas. Ese comportamiento se repitió durante la década de 1980 y, cuando se detenía a campesinos, hasta por haber dado un vaso de agua a un "contra», podían pasar hasta dos años hasta que los juzgaran ${ }^{71}$.

También Karla Sequeira, la coordinadora legal de la Comisión Permanente de Derechos Humanos (CPDH), declaró que entre las más de 3.000 denuncias contra la Seguridad del Estado que recibieron en la década de 1980, muchas fueron de personas acusadas injustamente sin juicios ni pruebas, muchas veces por las declaraciones de alguien que, bajo amenazas o para salvarse de la cárcel, testificaba en su contra. El mayor problema, según Sequeira, fue que muchos familiares de los guardias también fueron involucrados en los juicios populares, bajo el argumento de que eran cómplices y tenían conocimiento de los crímenes. Incluso se juzgó indiscriminadamente a personas en rangos irrelevantes dentro de las filas somocistas, como cocineros, médicos y personal administrativo por estar relacionados con otros más implicados ${ }^{72}$.

Asimismo, fue lamentable que quienes fueron considerados culpables y fueron encarcelados, estuvieron en el primer tiempo en condiciones materiales muy deficientes, en parte porque no había habido tiempo para cambiar ni instalaciones ni reglamentos. Después las circunstancias mejoraron, pero

${ }^{68}$ Catholic Institute..., 1987.

${ }^{69}$ Idem.

70 Envío Digital, 82 (Managua, 1988).

${ }^{71}$ Como contraste, véanse las recomendaciones del Informe Preliminar de la CIDH de la OEA en páginas posteriores.

${ }^{72}$ Nicaragua y la Stasi, Magazine (revista dominical del diario La Prensa), 112 (Managua, 2008): 12-19. 
inicialmente el descontrol fue absoluto y su situación recordaba en ciertos aspectos a la de la época somocista. Muestra de ello fue que la CIDH, tras una visita a Nicaragua, planteó a la JGRN algunas recomendaciones de carácter preliminar «en consideración a la urgencia que, en su concepto, ellas revisten» para mejorar la situación de los presos. Así se pusieron de manifiesto las deficiencias que soportaban los detenidos y la falta de garantías en lo referente a su defensa ante los tribunales especiales. El informe decía:

En materia de régimen carcelario, en el I del informe:

La CIDH visitó la mayoría de los centros de detención donde se encuentran los reos acusados o condenados por delitos no comunes y desea manifestar al Gobierno de Reconstrucción Nacional que -con excepción de la cárcel de mujeres Ruth Rodríguez en Granada- en general halló deplorables las condiciones de los reclusos, siendo incompatibles con los requerimientos mínimos necesarios para el respeto de la dignidad humana, según lo establece el artículo $8^{\circ} 2$-d del Estatuto sobre Derechos y Garantías de los Nicaraguenses y el Artículo $5^{\circ}-2$. de la convención Americana sobre Derechos Humanos ${ }^{73}$.

Efectivamente, cuando se leen con detenimiento las condiciones en que vivían los presos mencionadas en el texto anterior recuerdan, en parte, a las que denunciaban los presos políticos retenidos en la Central de Policía, en tiempos de Somoza ${ }^{74}$. Es probable que los dirigentes desconocieran dichas condiciones en medio del caos inicial, dado que permitieron las visitas de la $\mathrm{CIDH}$ sin poner objeciones. Lo cierto fue que no se ocuparon en ese tiempo de estas cuestiones

Otro grave defecto de esos tribunales, que motivó que los magistrados de la Corte Suprema los criticaran siempre, fue la existencia de algunas exculpaciones selectivas. Vilma Núñez recuerda a este respecto:

Algo que siempre me molestó muchísimo fue que esos tribunales actuaron siempre al margen de la ley, violando el derecho de defensa. Eran tribunales revanchistas y, por añadidura, todos los grandes criminales de la Guardia Nacional, los de las grandes responsabilidades, salieron tranquilamente del país, incluso muchos

73 "Informe Preliminar de la CIDH de la OEA a la Junta de Gobierno de Reconstrucción Nacional, 1980", Comisión Interamericana de Derechos Humanos (F. de V.: 22/10/2015). http:// www.cidh.org/countryrep/Miskitosesp/PrimeraPartea.htm.

${ }^{74}$ Dichas condiciones pueden leerse en la Carta colectiva de las presas de la Central de Policía [firmada por Margine Gutiérrez, María Auxiliadora, Gloria M. Traña, Charlotte Baltodano, Mónica Baltodano, Martha Isabel Cranshaw, Asunción Núñez Cruz (un campesino hondureño), Carlos Sequeira, Silvio Porras, Arnoldo E., Francisco Cuadra Serrano, Francisco Mercado Rojas, Adán Navarrete, María del Carmen Gómez y siete firmas ilegibles], Archivo del Centro de Historia Militar (ACHM), Colección Movimiento Revolucionario (MR), estante 001, caja 017, exp. 000527. 
que habían sido capturados. Tomás Borge los liberó. En cambio, los que quedaron presos, que fueron los guardias rasos, fue a los que se aplicó. Por eso nos opusimos siempre ${ }^{75}$.

En la misma línea, en el II, referido a la materia de derechos y garantías de la defensa, se añadía:

En caso de mantenerse los Tribunales Especiales, se recomienda: a) Que se establezca el recurso de revisión ante una autoridad judicial superior, que podría ser la Corte Suprema de Justicia o las Cortes de Apelaciones de las sentencias dictadas por los Tribunales Especiales, del que podrían hacer uso únicamente los acusados; b) Que se creen tribunales especiales departamentales para descongestionar los tribunales de Managua. c) Que las imputaciones o cargos a los sindicatos se hagan por hechos concretos sobre la base del resultado de las investigaciones previas, debiéndose indicar claramente en la acusación los nombres, fechas, lugares y demás circunstancias relativas a los hechos imputados; d) Que se modifique el Artículo 20 de la Ley 185 creadora de los Tribunales Especiales para que el Tribunal Especial de Apelación pueda revisar las sentencias condenatorias de primera instancia, y absolver o reducir las pena impuesta; e) Que se amplíen los términos para la preparación de la defensa y presentación de las pruebas; f) Que tanto los libelos de acusación como las sentencias sean motivadas, indicándose el delito, los hechos y las pruebas que en cada caso apoyen la acusación ${ }^{76}$.

En conclusión, se podría sintetizar el complejo proceso de organización institucional y conformación del Estado revolucionario, señalando que el poder ejecutivo - Junta de Gobierno (JGRN), permanentemente interferida por la Dirección Nacional del FSLN- fue quien realmente tuvo la capacidad de tomar las decisiones, mientras los otros poderes estuvieron sometidos al anterior. A lo largo de los diez años de gobierno revolucionario todavía se incrementaría más la presencia de la Dirección Nacional, justificada siempre por las necesidades de defensa de la «Guerra de la Contra», respaldada fuertemente por la administración Reagan. Dicha situación coadyuvó a la seguridad de que las actitudes y medidas tomadas por la dirigencia quedaban legitimadas con el argumento de que «la revolución es fuente de Derecho». Del mismo modo, esa organización vertical y al servicio de las necesidades de la guerra, fue causa de la prolongación de los privilegios de los Ministerios de Defensa e Interior, por ser realmente imprescindibles en ese contexto. Especialmente el de Defensa pudo actuar, en la práctica, de modo absolutamente independiente del Gobierno; sin tener que dar cuentas de su gestión a ninguna otra instancia y con una asignación de gastos que excedía en mucho la del resto de los Ministerios. Esta circunstancia tendría serias consecuencias posteriores.

75 Entrevista de la autora con Vilma Núñez, Managua, enero de 2012,

76 "Informe Preliminar de la CIDH de la OEA a la Junta de Gobierno de Reconstrucción Nacional, 1980"; Comisión Interamericana de Derechos Humanos. Ver nota 73. 
Como resultado de las modificaciones estructurales de los tres primeros años tras el triunfo de la revolución, entre 1979 y 1982, el FSLN fue dejando en el camino a sus compañeros de la lucha antisomocista. Junto a ello, el ingrediente de la guerra y sus prioridades motivó que los sandinistas pasaran de considerarse la vanguardia de la revolución a creer que la revolución solo eran ellos. A partir de ese momento, para muchos de entre las filas sandinistas, quienes les cuestionaran sus métodos o decisiones, serían considerados contrarrevolucionarios. Sin embargo, solo a los dos años del triunfo de la revolución, la coyuntura económica y la urgencia de la más amplia aceptación internacional, les impulsarían a recuperar el pragmatismo de antaño y dar un giro a su trayectoria: convocar las primeras elecciones de 1984.

\section{BIBLIOGRAFÍA}

Álvarez Montalván, Emilio, "La Década Sandinista”, Debats, Número Extra 1, dedicado a Especial Nicaragua, (Barcelona, 1996): 37 ss.

Amnistía Internacional, Informe de las misiones de Amnistía Internacional a la Republica de Nicaragua. Agosto de 1979, enero de 1980 y agosto de 1980, Londres, Centro de Documentación de Amnistía Internacional, 1981.

Babb, Florence, Después de la revolución. Género y cultura política en la Nicaragua neoliberal, Managua, IHNCA-UCA, 2012.

Bataillon, Gilles, Génesis de las guerras intestinas en América Central (1960-1983), México, Fondo de Cultura Económica, 2008.

Carrillo Salcedo, Juan Antonio, Dignidad frente a barbarie. La Declaración Universal de Derechos Humanos, cincuenta años después, Madrid, Trotta, 1999.

Catholic Institute for International Relations (CIIR): "Right to Survive-Human Rights in Nicaragua", Envío Digital, 76 (Managua, 1987).

Close, David, Nicaragua, Politics, Economics and Society, Londres, Frances Piner, 1988.

Christian, Shirley, Nicaragua: Revolution in the Family, New York, Vintage, 1981.

Echeverría, Juan José, La guerra no declarada, Costa Rica, Editorial Universidad Estatal a Distancia (EAUNED), 2006.

Esgueva Gómez, Antonio, Las Constituciones Políticas y sus Reformas en la Historia de Nicaragua (2 tomos), Managua, Instituto de Historia de Nicaragua y Centroamérica (IHNCA-UCA), 2002.

Esgueva Gómez, Antonio, Historia Constitucional de Nicaragua, Managua, Lea Grupo Editorial, 2003. 
Fonseca, Carlos, Obras: Bajo la bandera del sandinismo, Managua, Editorial Nueva Nicaragua, 1985.

Gilbert, Dennis, Sandinistas, The Party and the Revolution, New York, Basil Blakwell, 1988.

Guevara, Onofre, Cien años de movimiento social en Nicaragua, Managua, NitlapanUCA, 2007.

Marti i Puig, Salvador y Close, David (eds.), Nicaragua y el FSLN (1979-2009). ¿Qué queda de la revolución?, Barcelona, Bellaterra, 2009.

Mc Connell, S. A., "La evolución incierta del sistema electoral nicaragüense", Salvador Marti i Puig y David Close, (eds.), Nicaragua y el FSLN (1979-2009). ¿Qué queda de la revolución?, Barcelona, Bellaterra, 2009.

Nolan, David, La ideología sandinista y la revolución nicaragüense, Barcelona, Ediciones 29, 1986.

Núñez Escorcia, Vilma, "La crisis del FSLN", Envio Digital, 214 (Managua, 2000).

Oettler, Anika, "Justicia tradicional y los significados de la elaboración del pasado nicaragüense", Encuentro, 95 (Managua, 2013): 7-27.

Ortíz Treviño, Rigoberto Gerardo, "Los Juicios de Nuremberg 60 años después", Biblioteca Jurídica Virtual del instituto de Investigaciones Jurídicas, www.juridicas. unam.mx (Fecha de verificación: 15 de septiembre de 2015).

Pérez Baltodano, Andrés, Entre el Estado Conquistador y el Estado Nación. Providencialismo, pensamiento político y estructuras de poder en el desarrollo histórico de Nicaragua, Managua, IHNCA-UCA, 2003.

Ramírez, Sergio, Adiós Muchachos. Una memoria de la revolución sandinista, Managua, Anamá, 1998.

Randall, Margaret, Las hijas de Sandino. Una historia abierta, Managua, Anamá, 1999.

Fecha de recepción: 9 de agosto de 2013.

Fecha de envío de las modificaciones: 6 de febrero de 2014.

Fecha de aceptación: 3 de marzo de 2014. 


\section{The Institutional Design of the Sandinista State (1979-1982): The Revolution as a Resource of Law}

While the institutions of the new revolutionary state were emerging in Nicaragua, an element which would remain constant throughout the 1980s was taking shape: the pre-eminence of the executive power and the loss of the initial support of the Sandinista National Liberation Front (FSLN). At the same time, the understanding between Nicaragua and the US, which was already complicated within the context of the Cold War, worsened during this period. This paper aims to elucidate the various factors which caused the imbalance in the distribution of powers within Sandinista institutions.

KEY WORDS: Sandinista National Liberation Front (FSLN); Board of National Reconstruction; Ronald Reagan; National Direction; Nicaraguan Contra War. 